\title{
Supramolecular architecture through self-organization of Janus-faced homoazanucleosides
}

Umesh K. Mishra, ${ }^{a}$ Yogesh S. Sanghvi, ${ }^{\mathrm{b}}$ Martin Egli, ${ }^{\mathrm{c}}$ and Namakkal G. Ramesh ${ }^{\mathrm{a}}$

aDepartment of Chemistry, Indian Institute of Technology Delhi, Hauz Khas, New Delhi 110016, India.

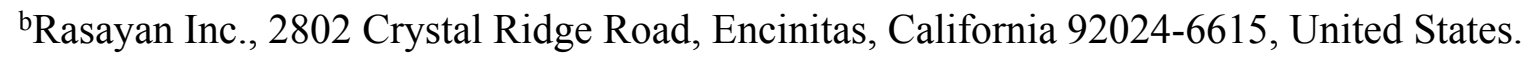

'Department of Biochemistry, School of Medicine, Vanderbilt University, Nashville, Tennessee 37232, United States.

$$
\text { E.mail: } \quad \text { ramesh@chemistry.iitd.ac.in }
$$


Table of contents

\begin{tabular}{|l|l|c|}
\hline Figures/Tables & \multicolumn{1}{|c|}{ Description } & Pages \\
\hline Figures S1-S38 & Copies of ${ }^{1} \mathrm{H}$ and ${ }^{13}$ C NMR spectra of all new compounds & S3-S40 \\
\hline & Procedure for crystal growth and crystal data collection & S41 \\
\hline Table S1 & Crystal data and structure refinement parameters for 10, 2 and 21 & S42 \\
\hline Figure S39 & ORTEP plot of the crystal structure of 10 & S43 \\
\hline Figure S40 & ORTEP plot of the crystal structure of 2.HCl & S44 \\
\hline Figure S41 & ORTEP plot of the crystal structure of 21 & S \\
\hline
\end{tabular}




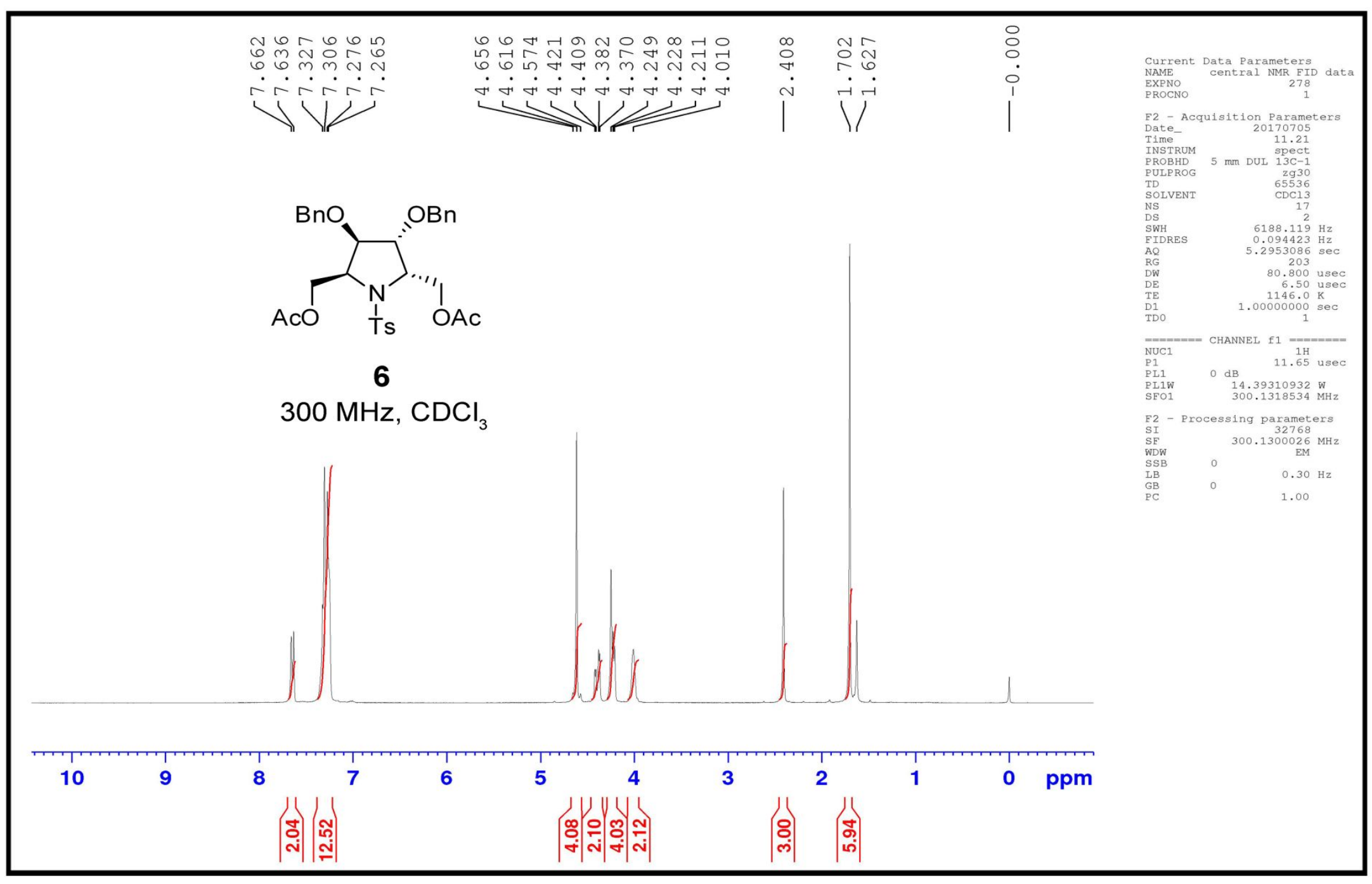

Figure S1: ${ }^{1} \mathrm{H}-\mathrm{NMR}$ spectrum of compound $\mathbf{6}$. 


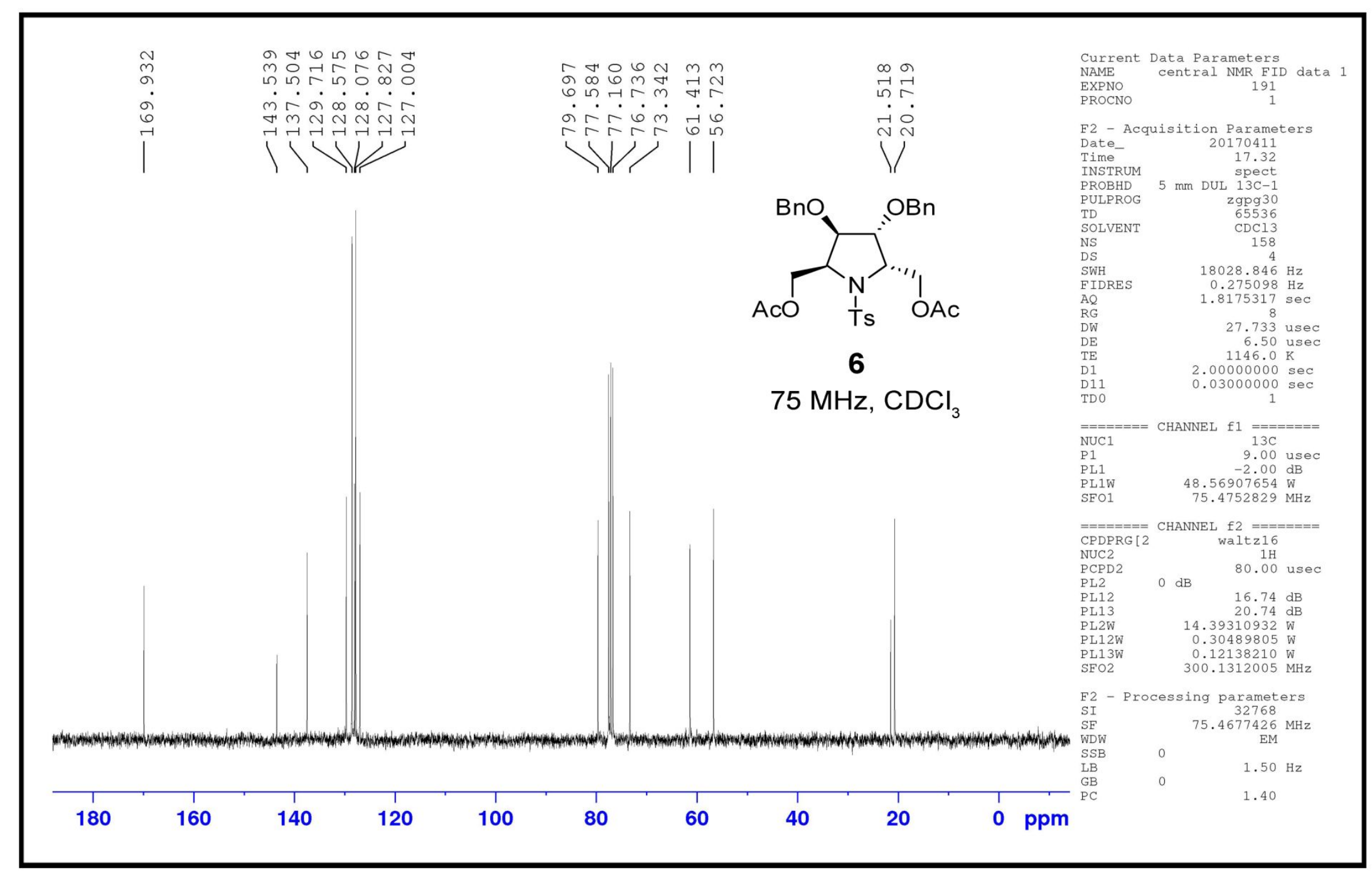

Figure S2: ${ }^{13} \mathrm{C}-\mathrm{NMR}$ spectrum of compound $\mathbf{6}$. 


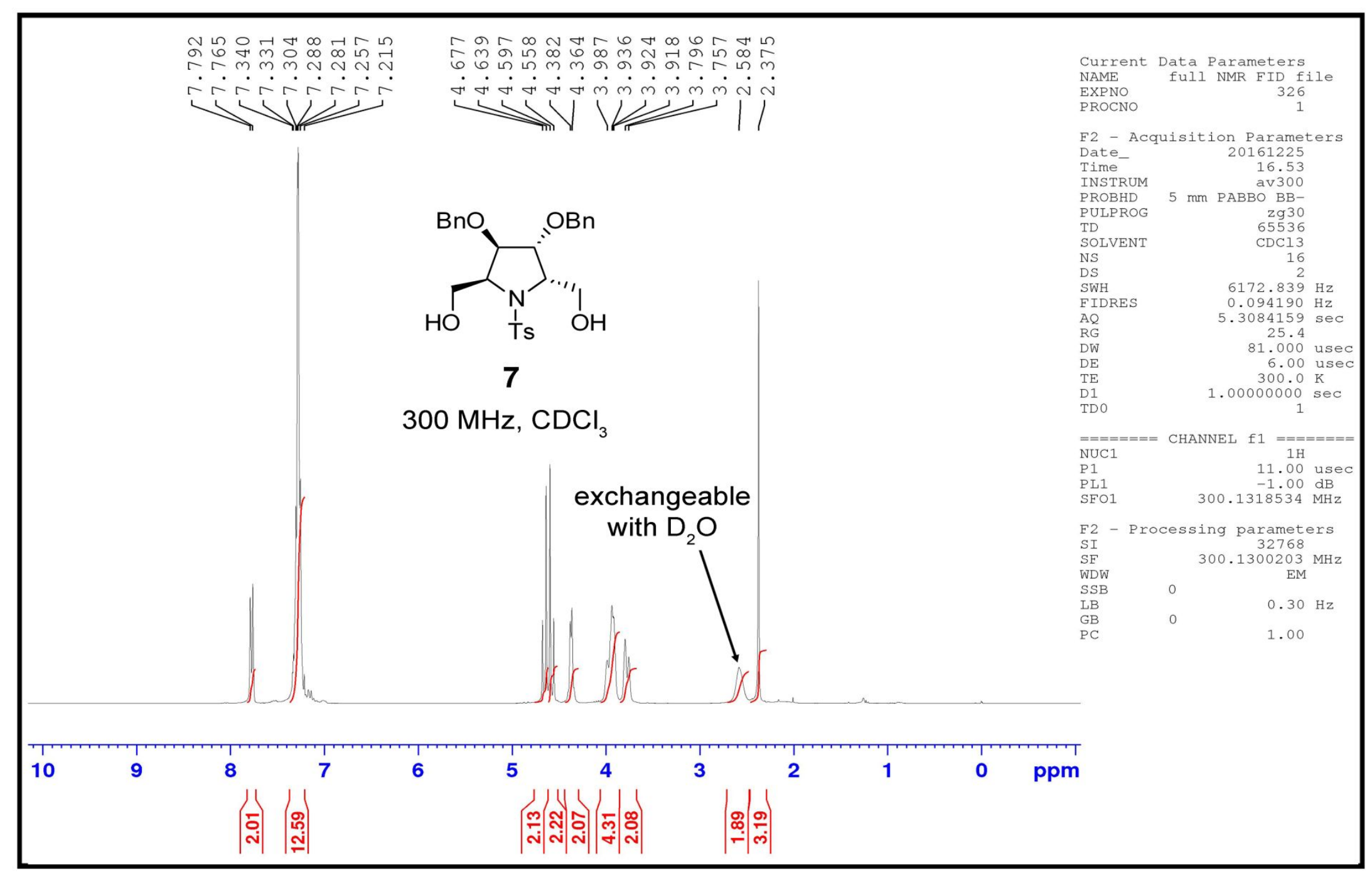

Figure S3: ${ }^{1} \mathrm{H}-\mathrm{NMR}$ spectrum of compound 7. 


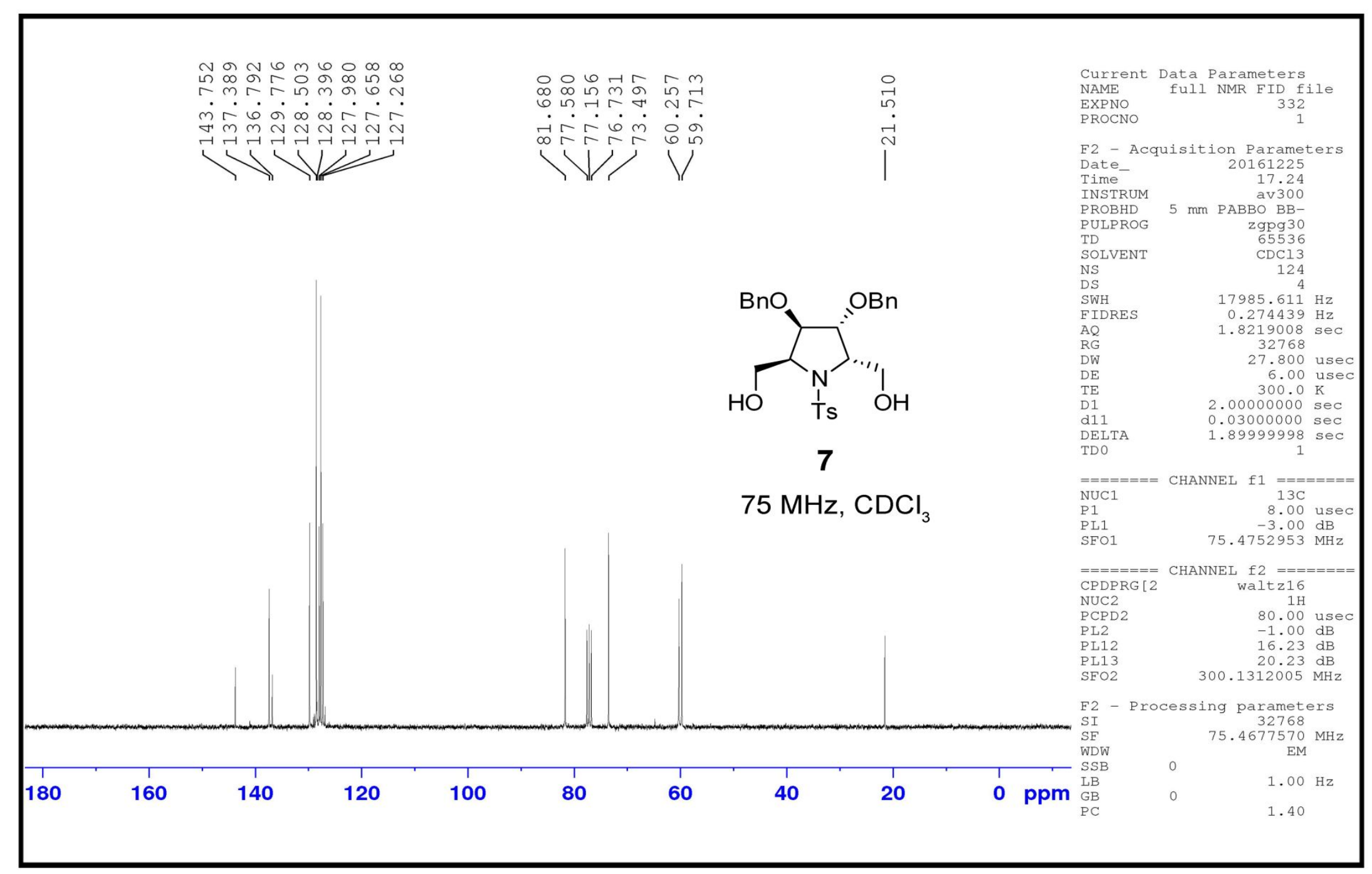

Figure S4: ${ }^{13} \mathrm{C}-\mathrm{NMR}$ spectrum of compound 7. 


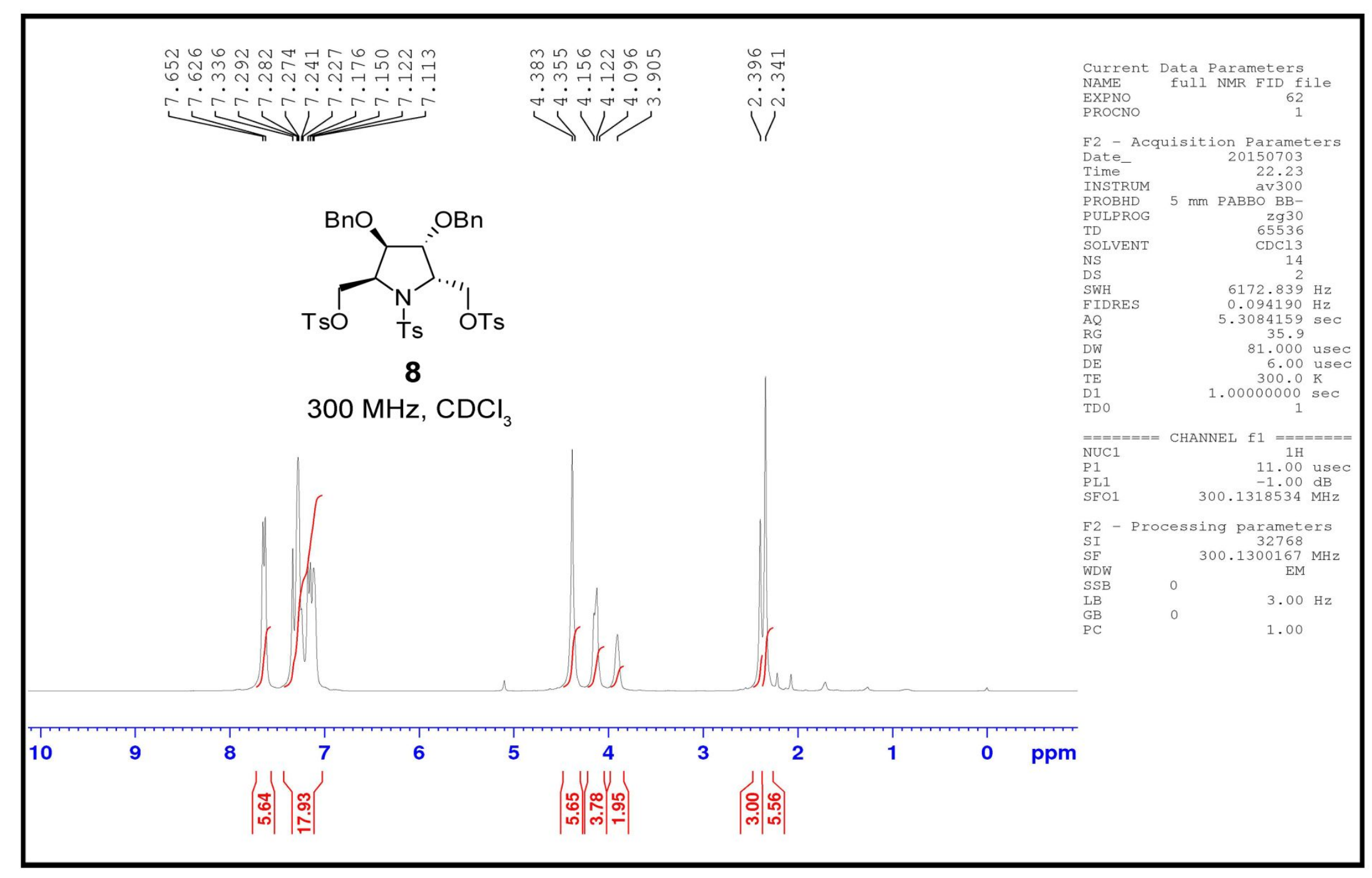

Figure S5: ${ }^{1} \mathrm{H}-\mathrm{NMR}$ spectrum of compound $\mathbf{8}$. 


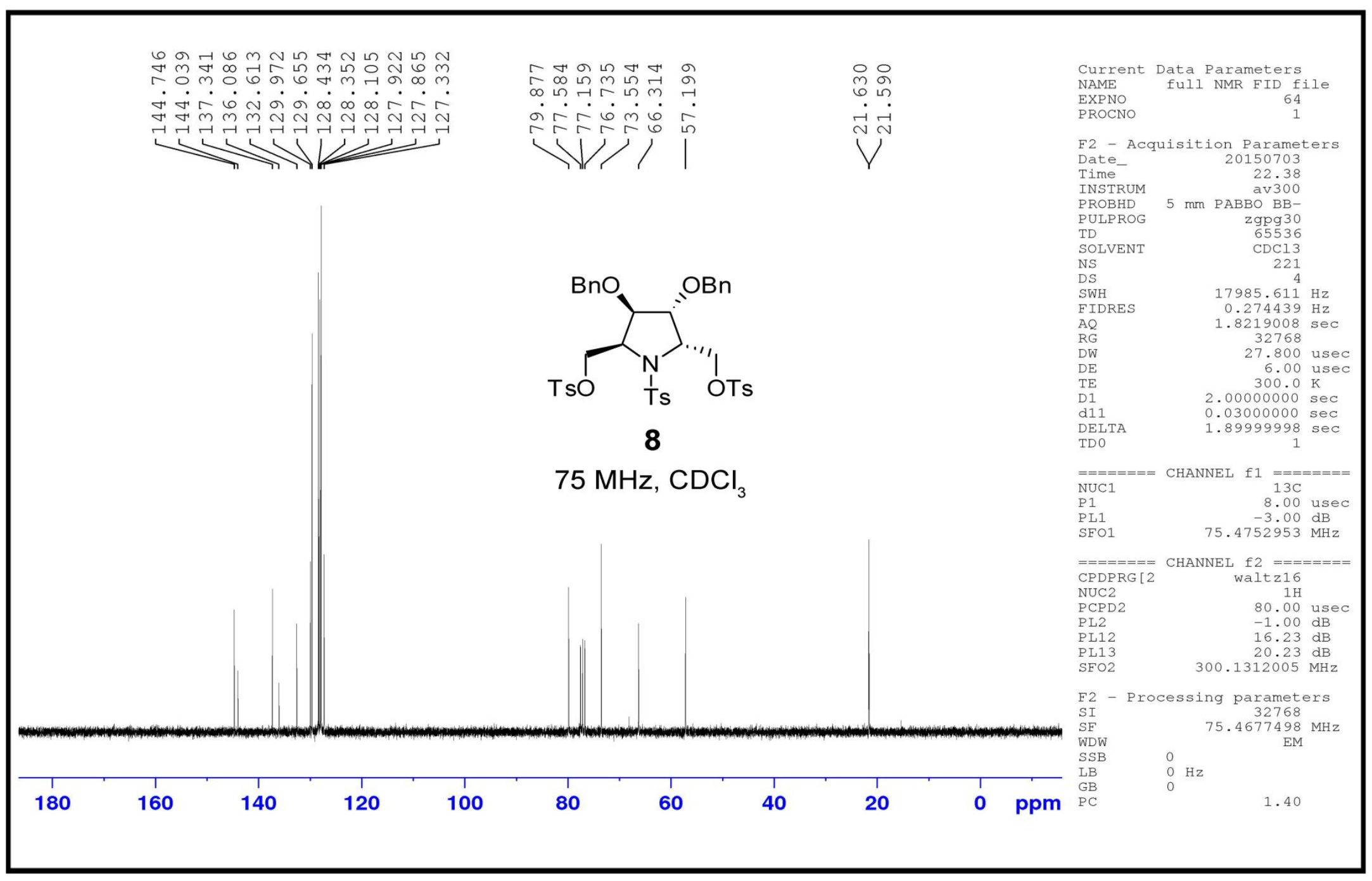

Figure S6: ${ }^{13} \mathrm{C}-\mathrm{NMR}$ spectrum of compound $\mathbf{8}$. 


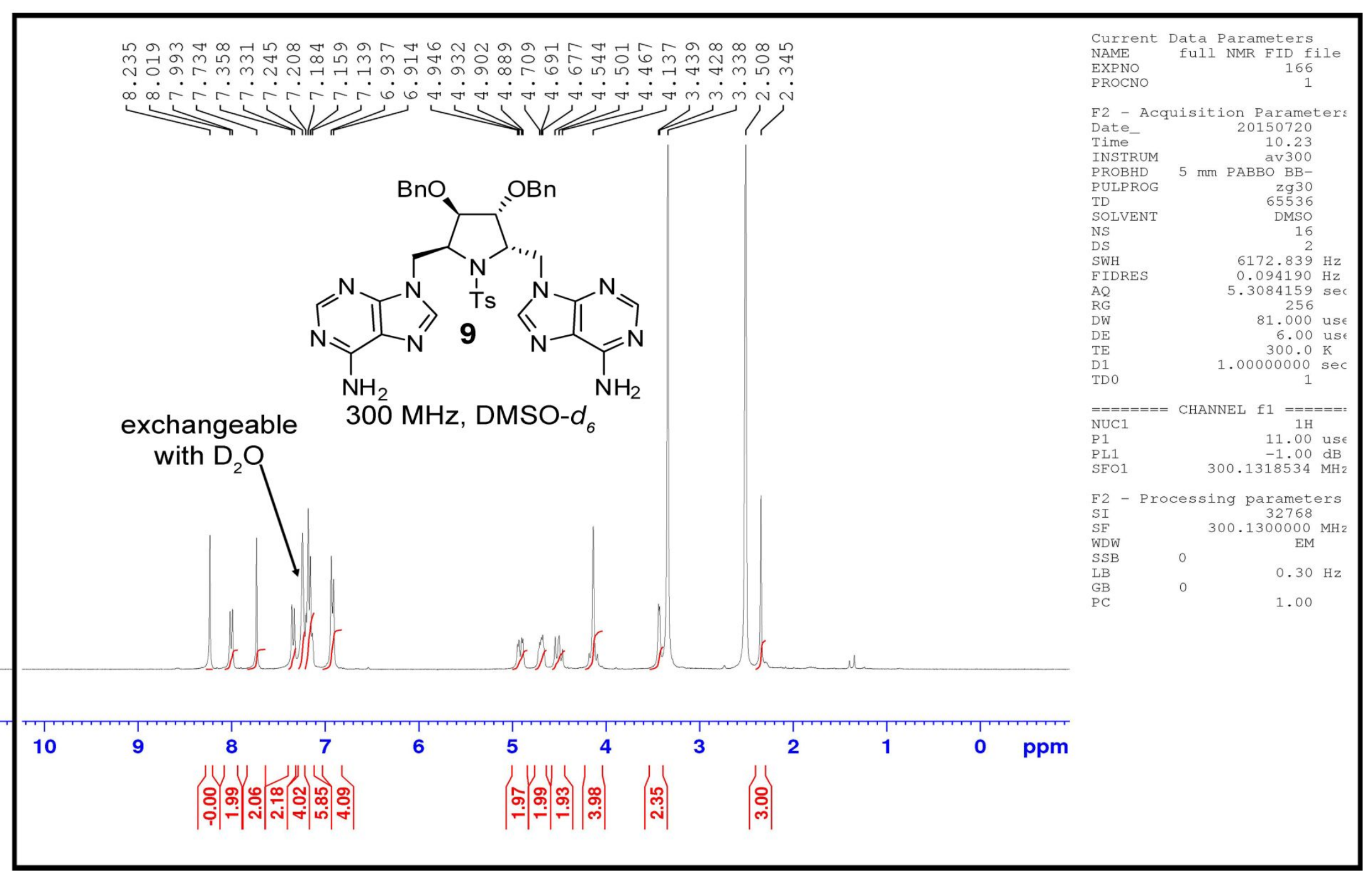

Figure S7: ${ }^{1} \mathrm{H}-\mathrm{NMR}$ spectrum of compound 9. 


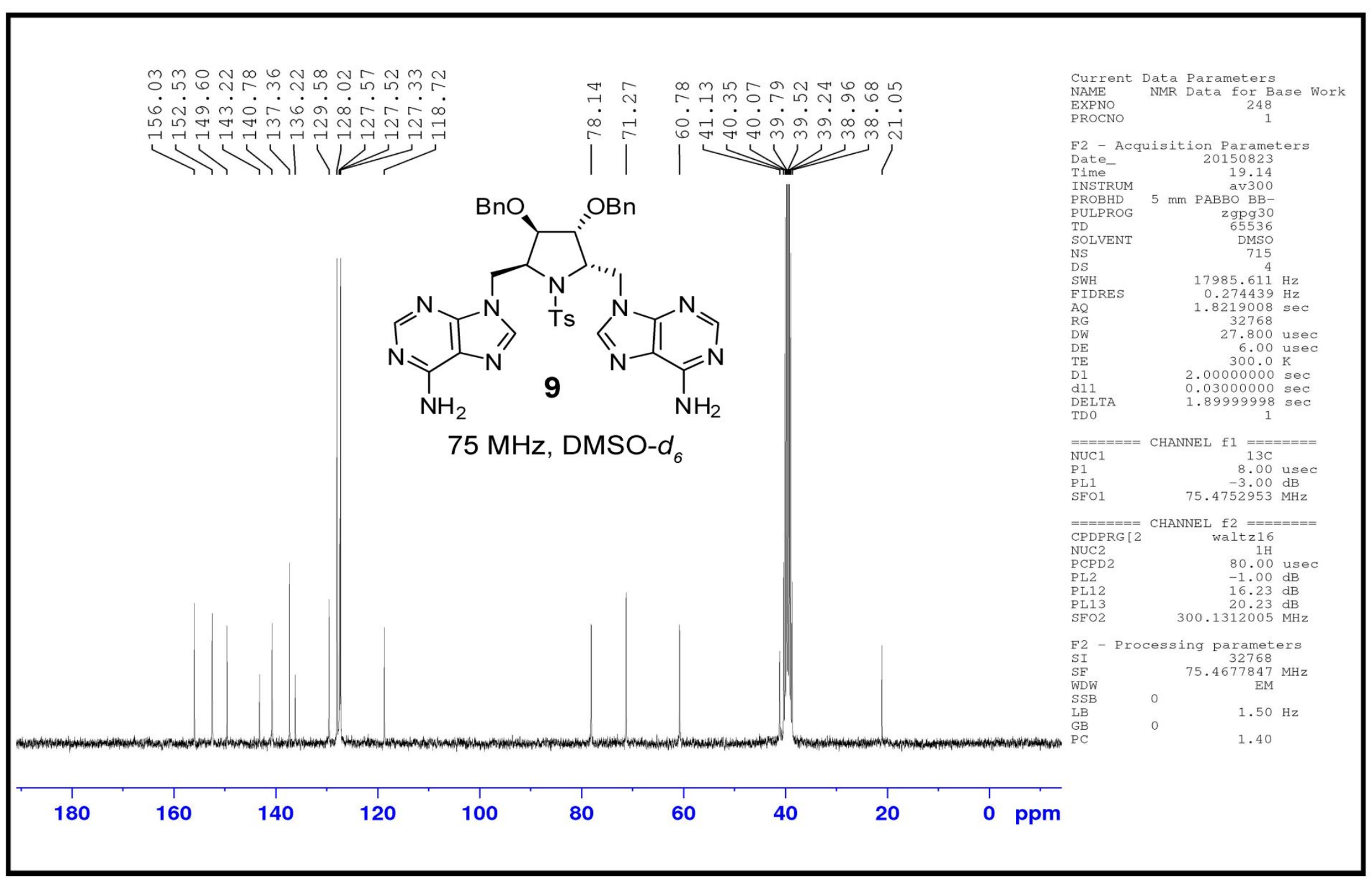

Figure S8: ${ }^{13} \mathrm{C}-\mathrm{NMR}$ spectrum of compound 9. 


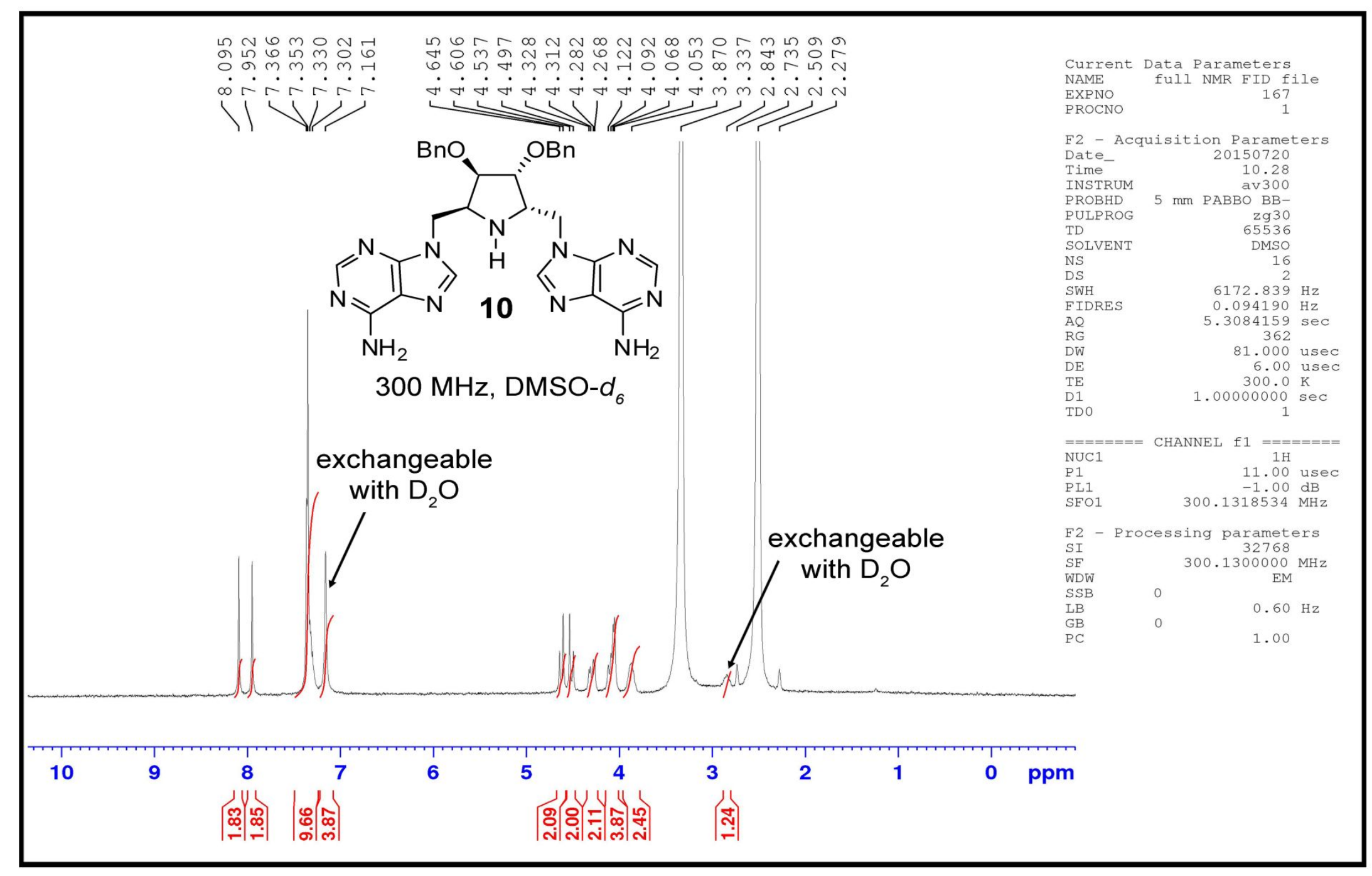

Figure S9: ${ }^{1} \mathrm{H}-\mathrm{NMR}$ spectrum of compound $\mathbf{1 0}$. 


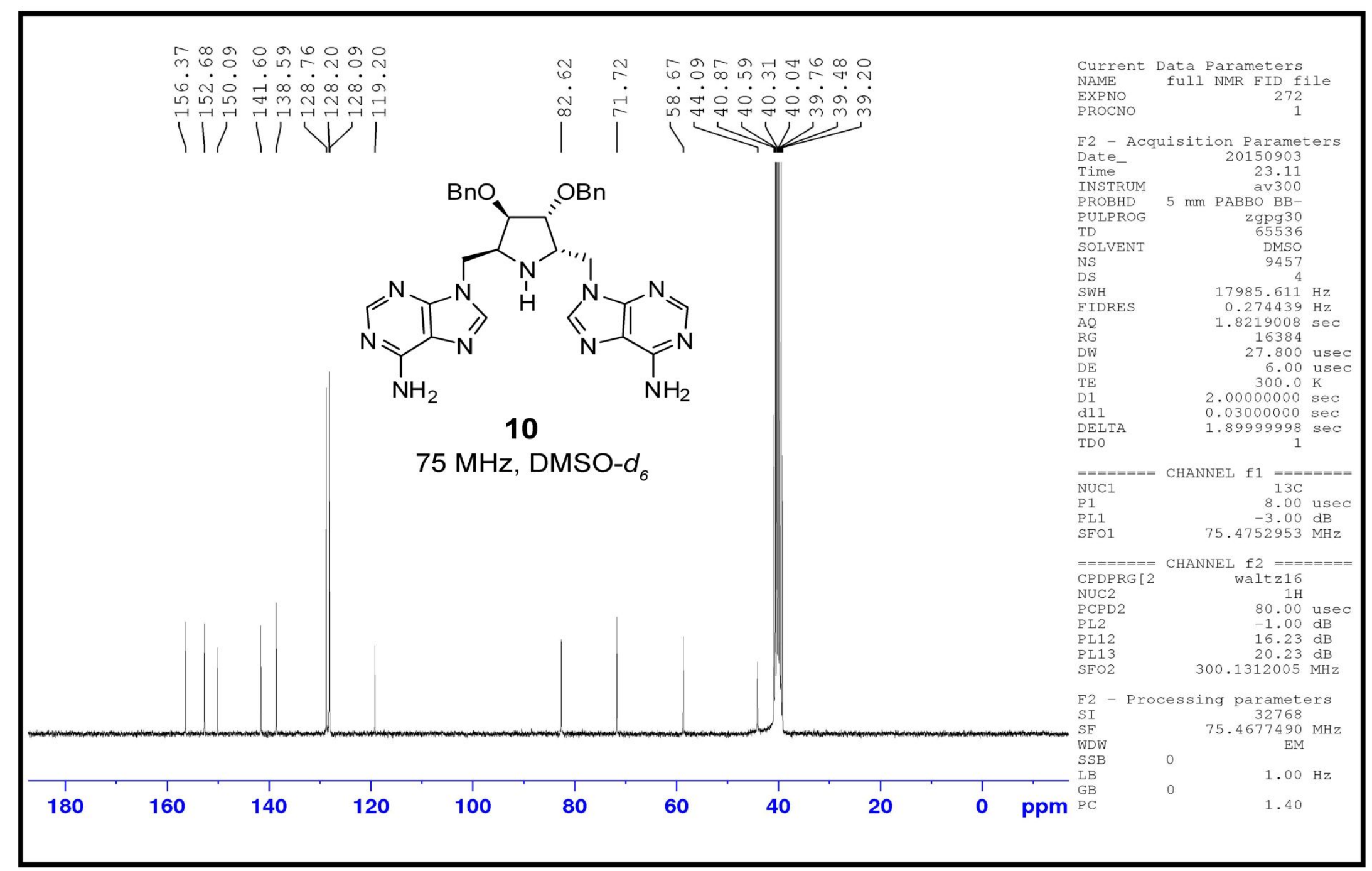

Figure S10: ${ }^{13} \mathrm{C}-\mathrm{NMR}$ spectrum of compound $\mathbf{1 0}$. 


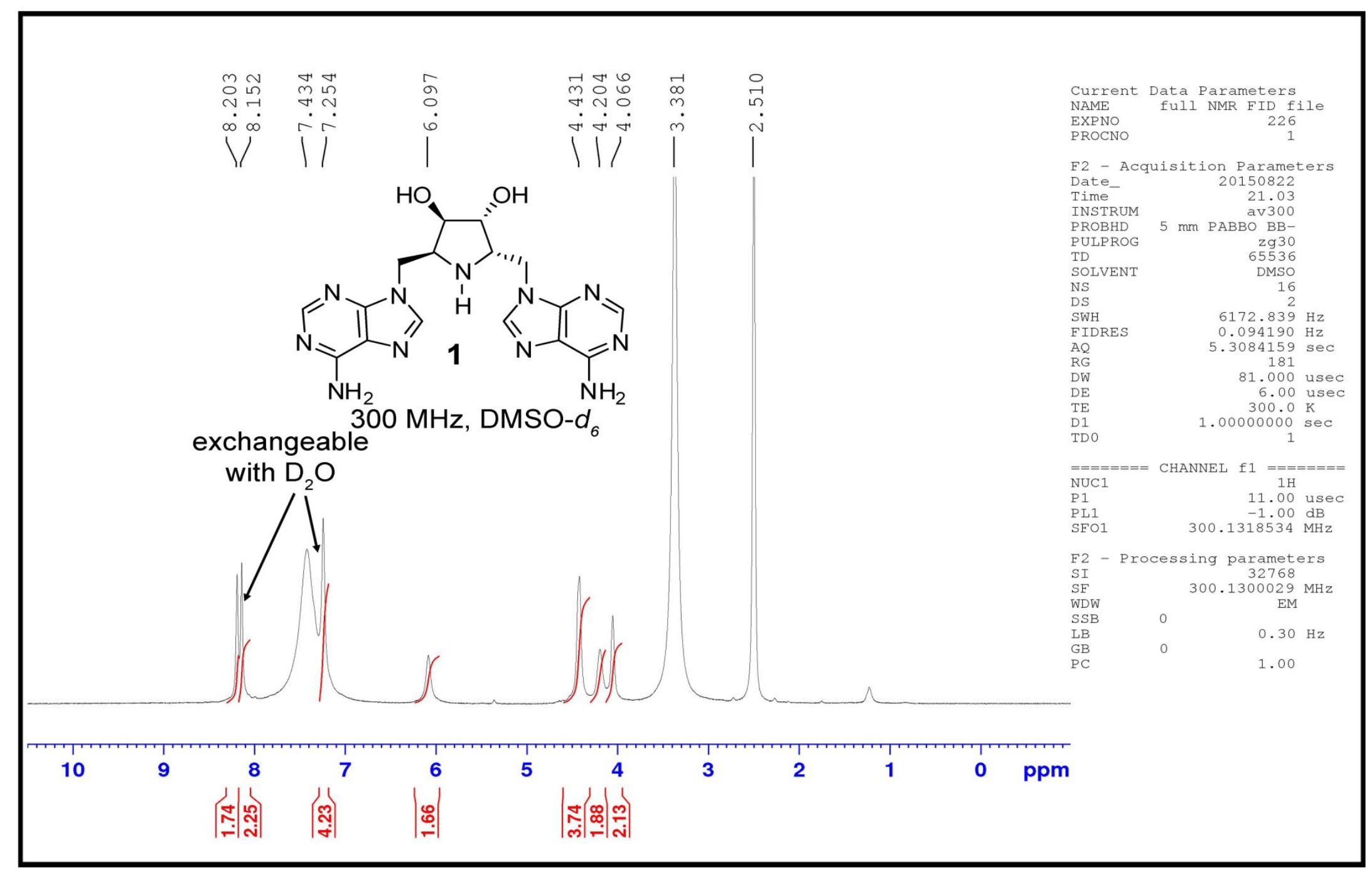

Figure S11: ${ }^{1} \mathrm{H}-\mathrm{NMR}$ spectrum of compound $\mathbf{1}$. 


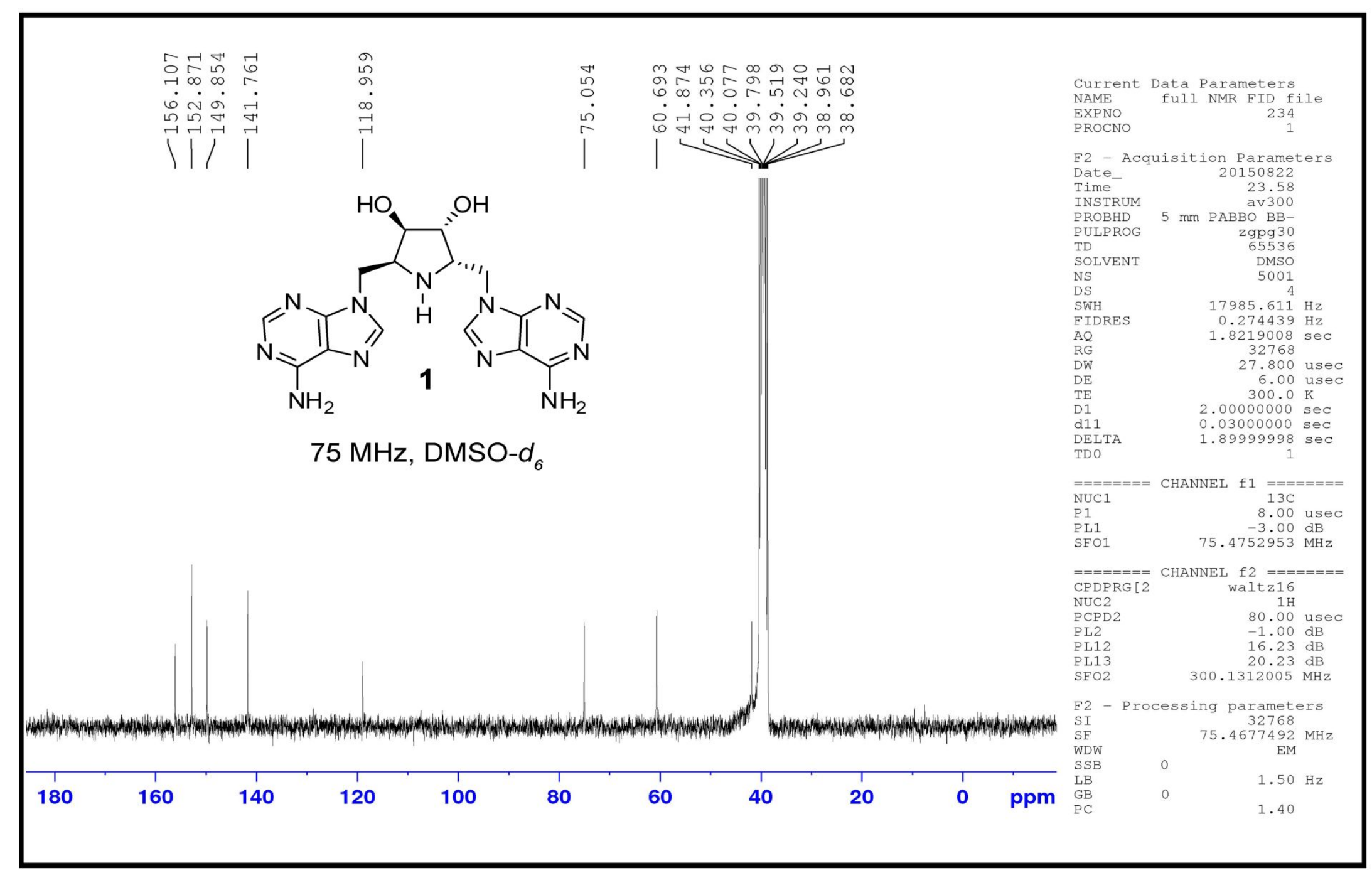

Figure S12: ${ }^{13} \mathrm{C}-\mathrm{NMR}$ spectrum of compound 1. 


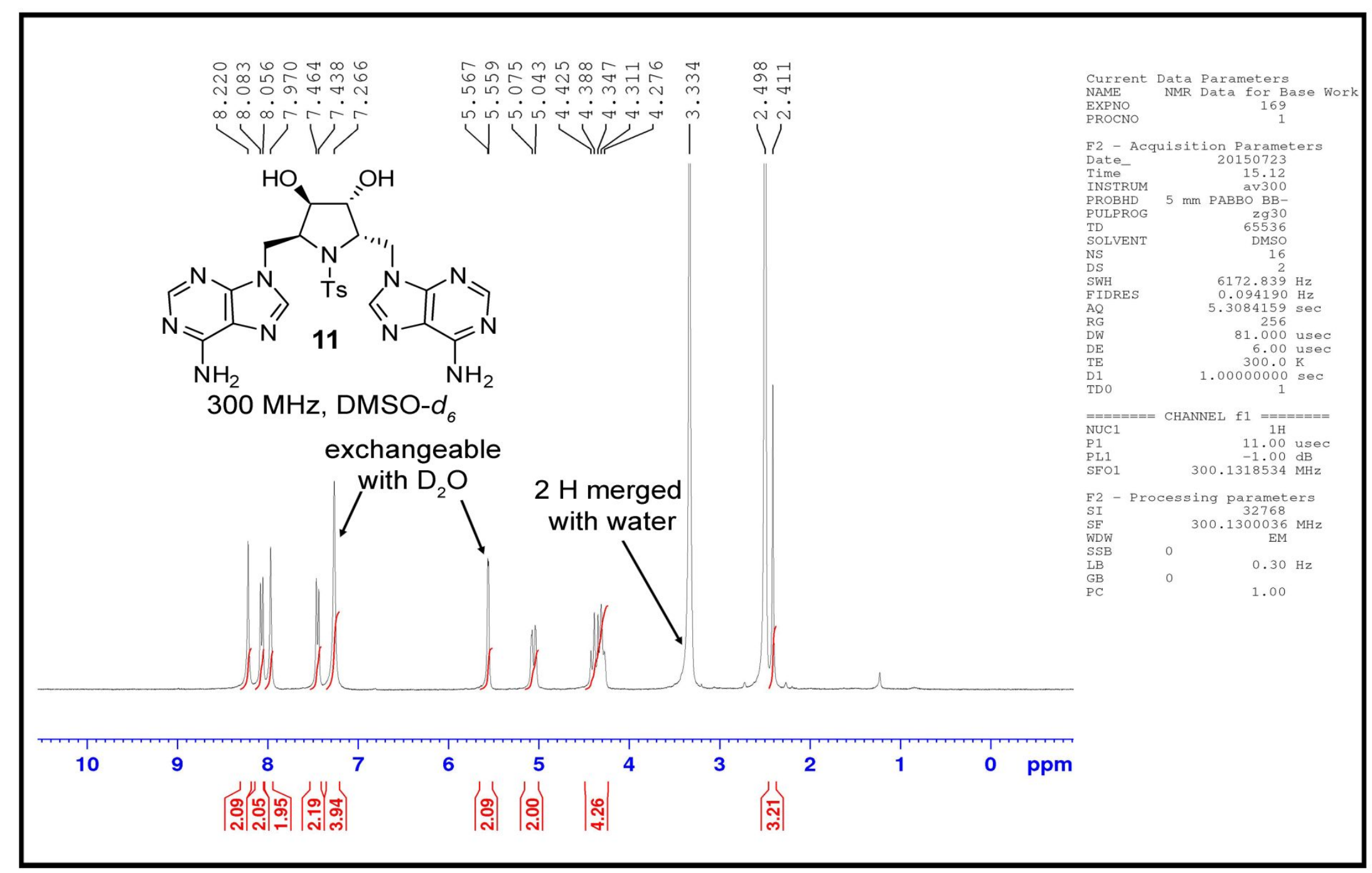

Figure S13: ${ }^{1} \mathrm{H}-\mathrm{NMR}$ spectrum of compound 11. 


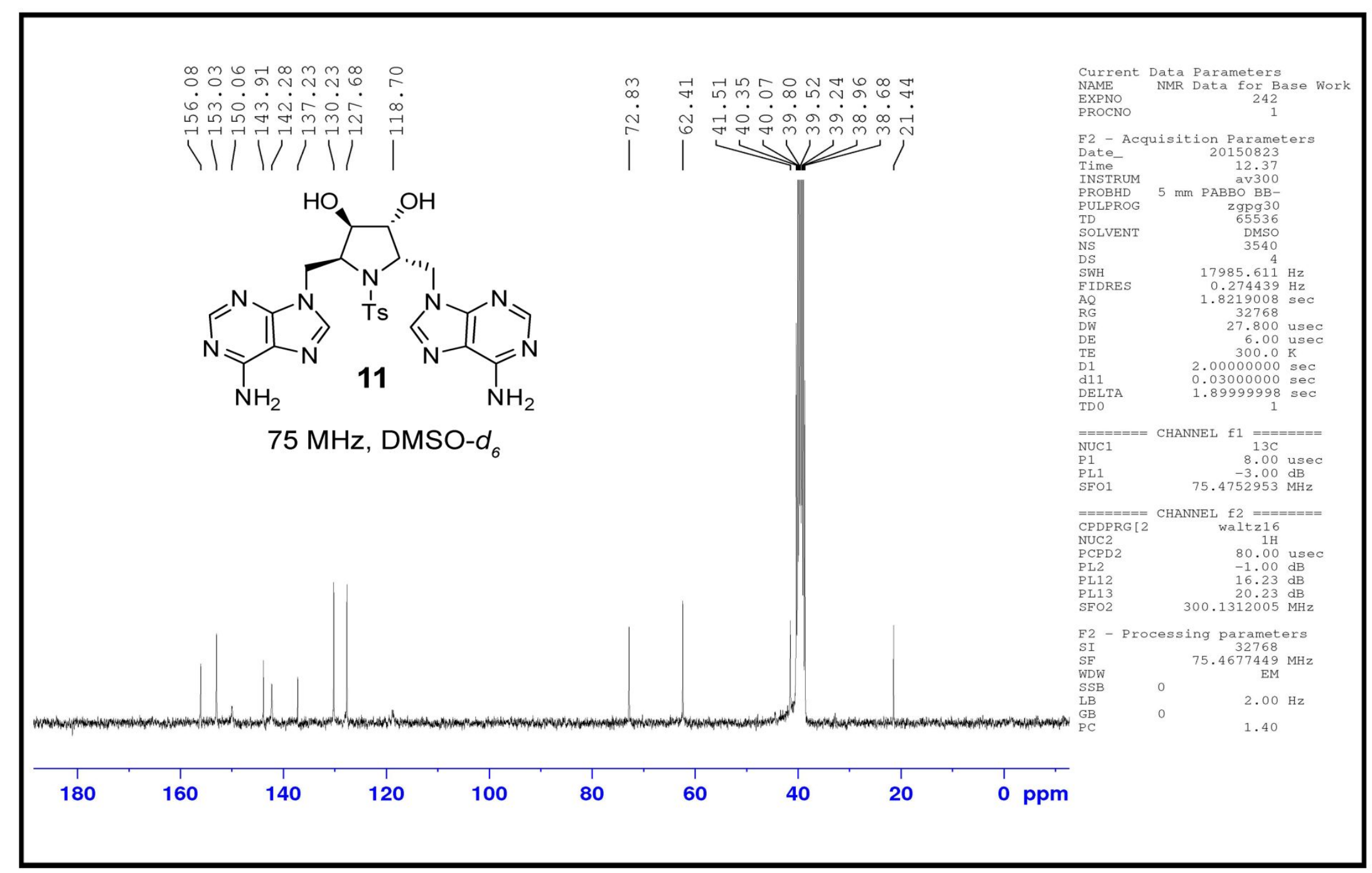

Figure S14: ${ }^{13} \mathrm{C}-\mathrm{NMR}$ spectrum of compound 11. 


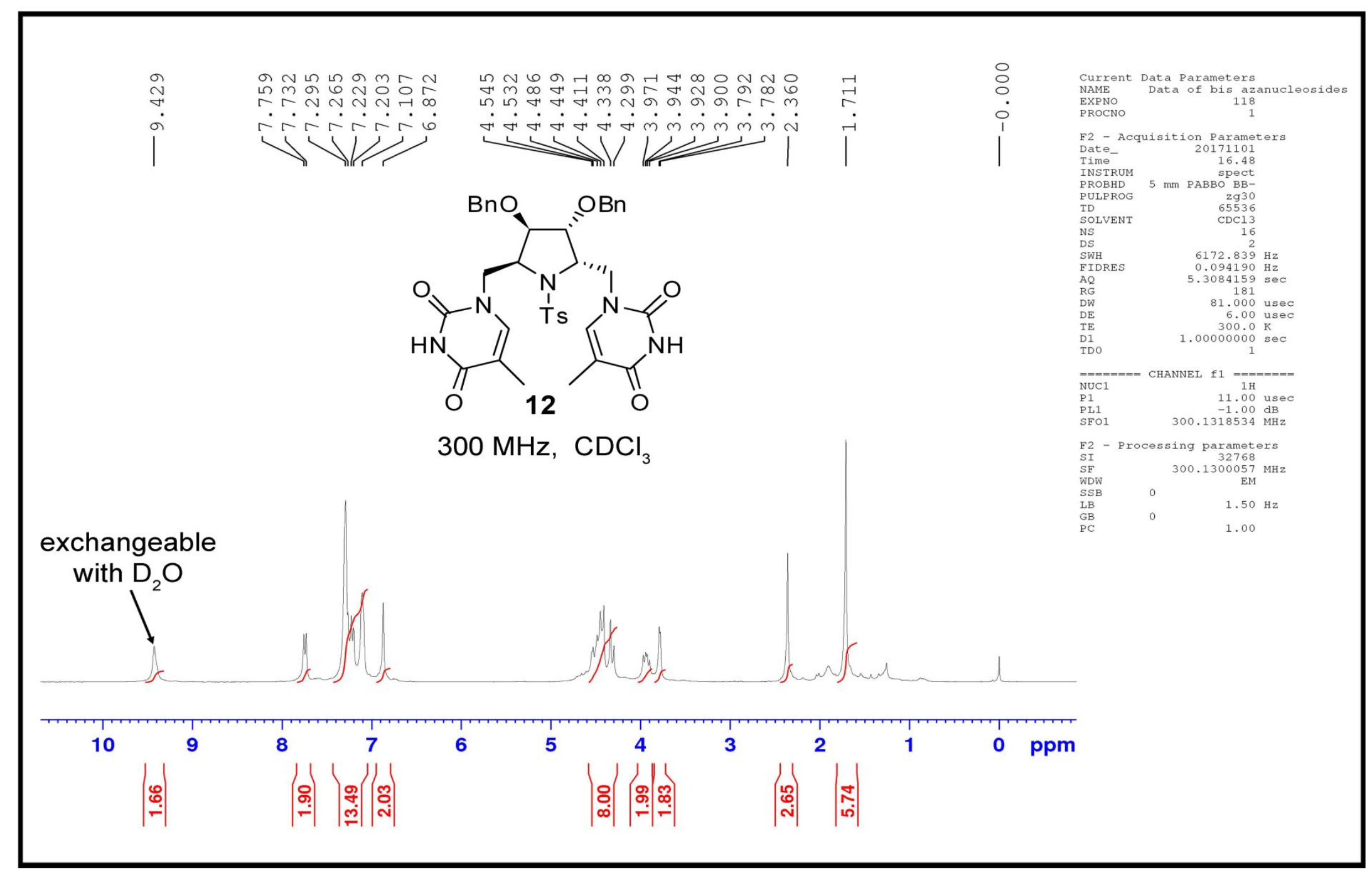

Figure S15: ${ }^{1} \mathrm{H}-\mathrm{NMR}$ spectrum of compound 12. 


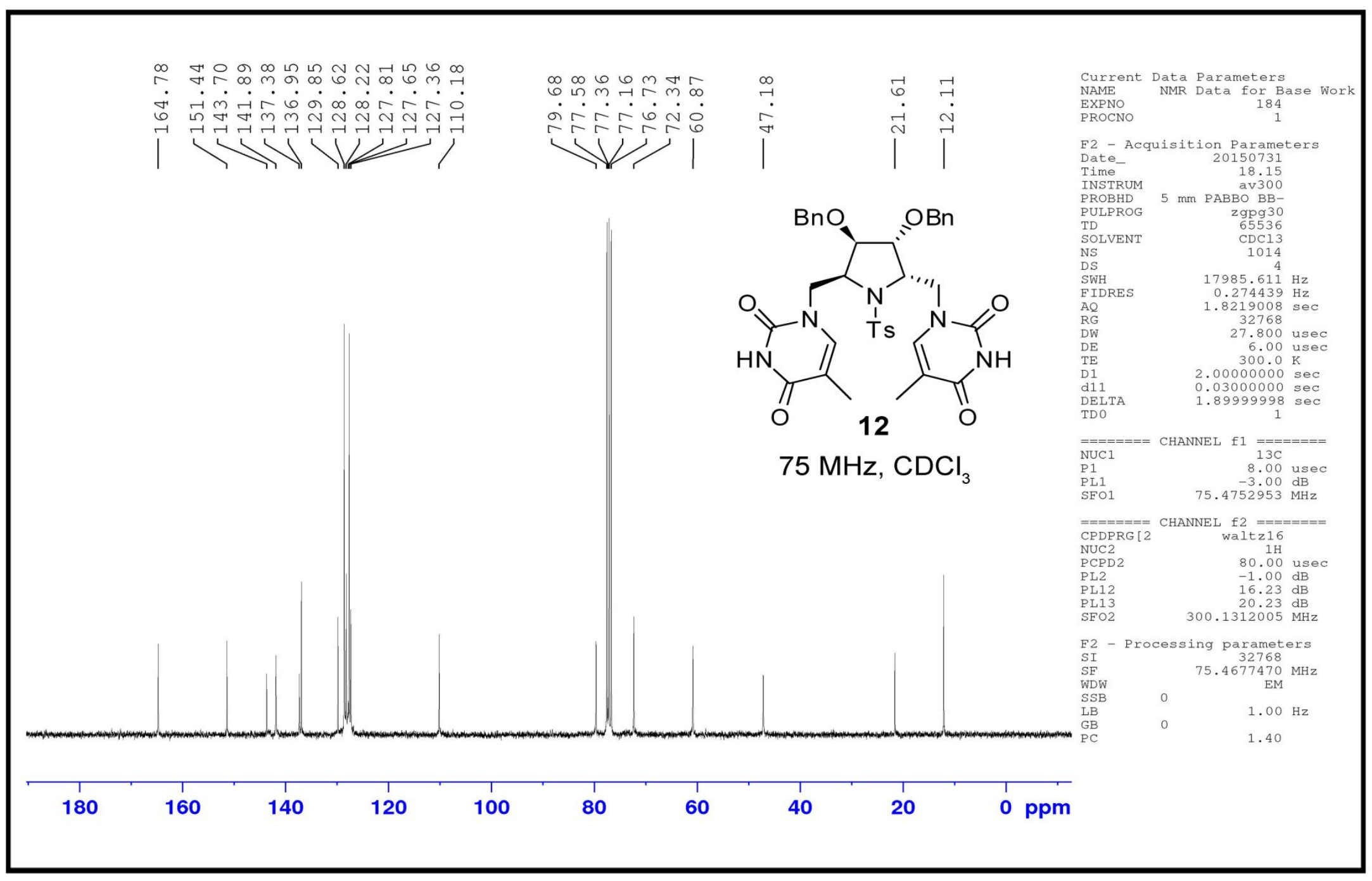

Figure S16: ${ }^{13} \mathrm{C}-\mathrm{NMR}$ spectrum of compound 12. 


$$
\text { 篮 }
$$




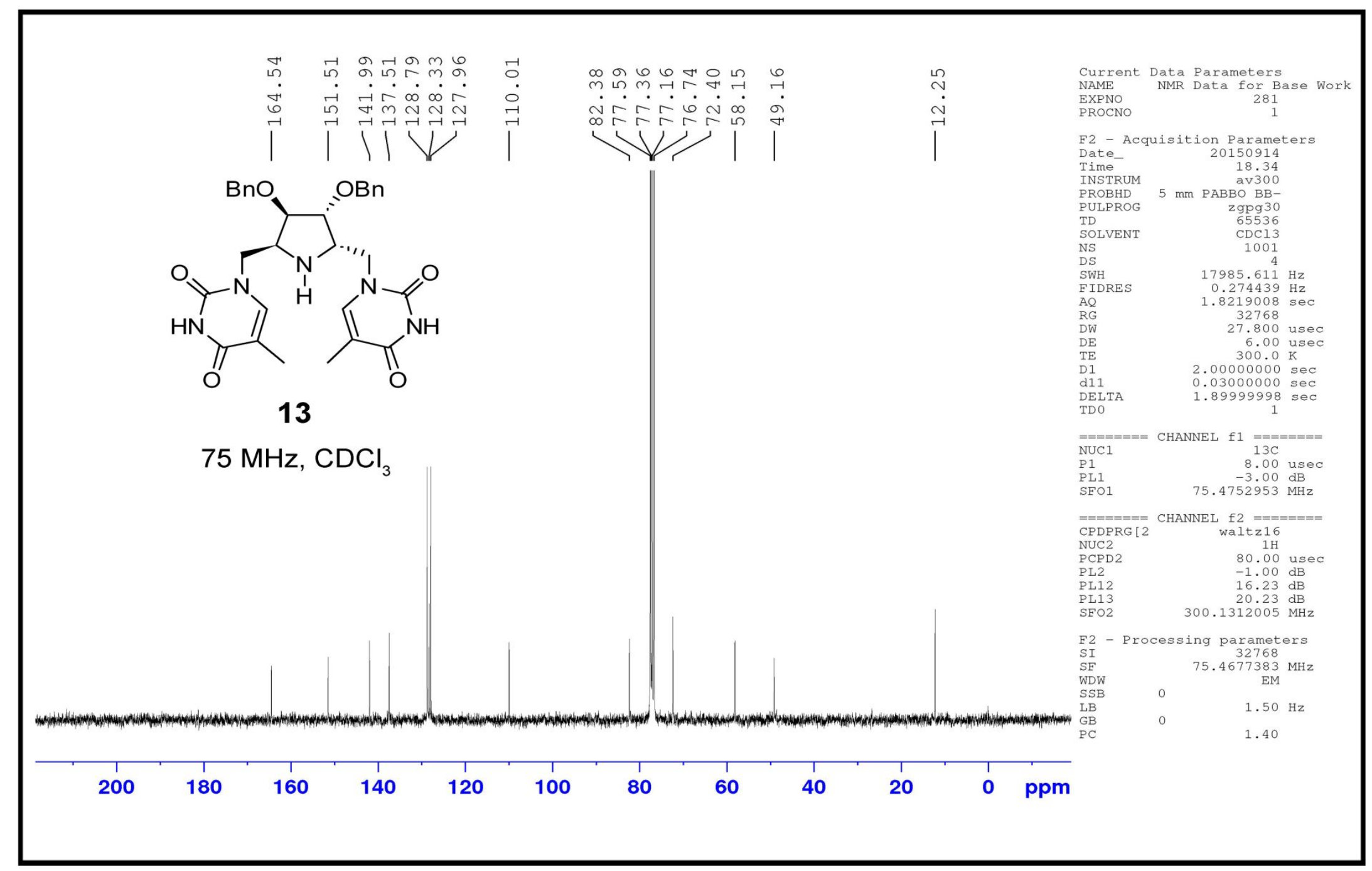

Figure S18: ${ }^{13} \mathrm{C}-\mathrm{NMR}$ spectrum of compound 13. 


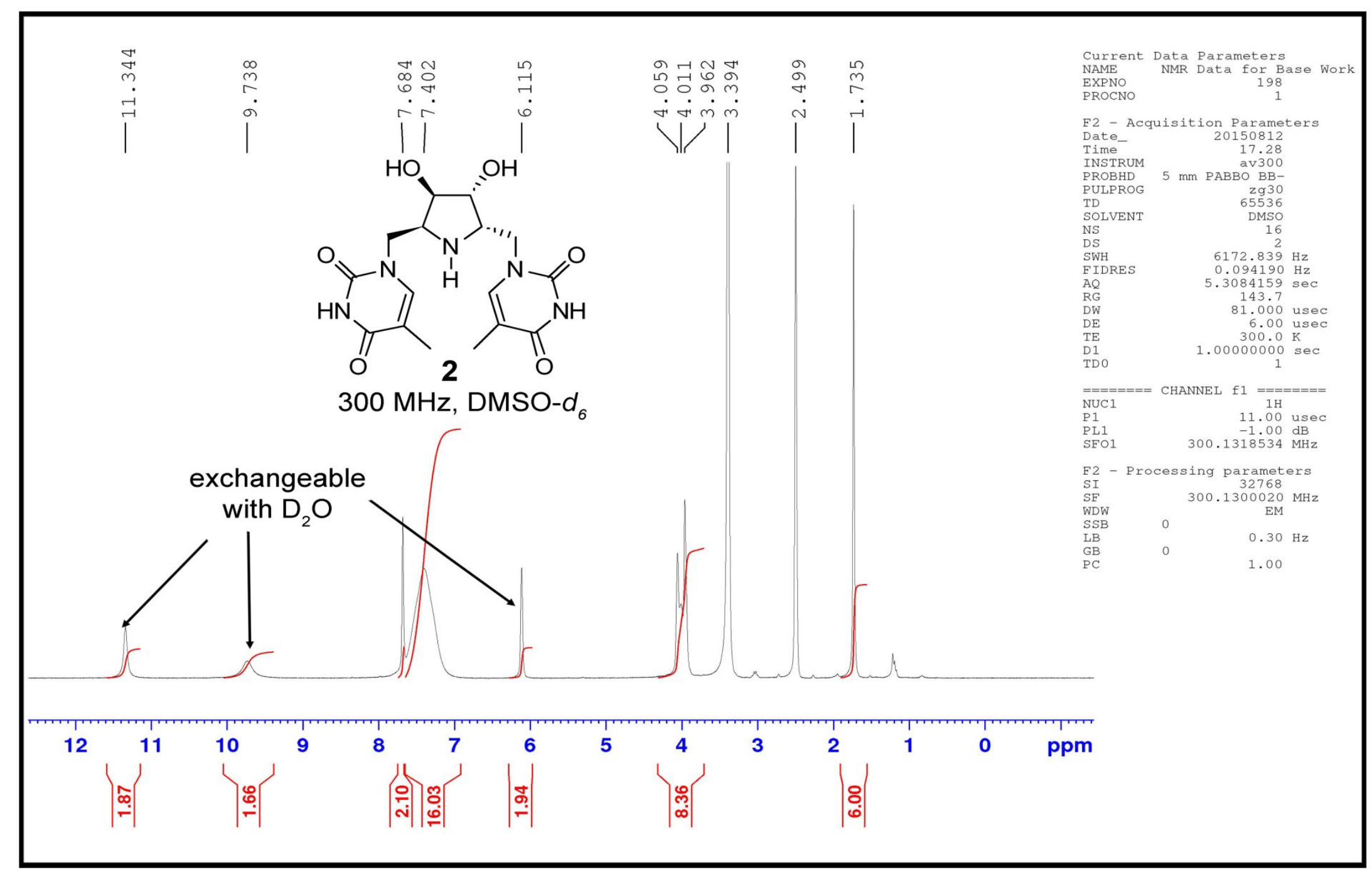

Figure S19: ${ }^{1} \mathrm{H}-\mathrm{NMR}$ spectrum of compound 2. 


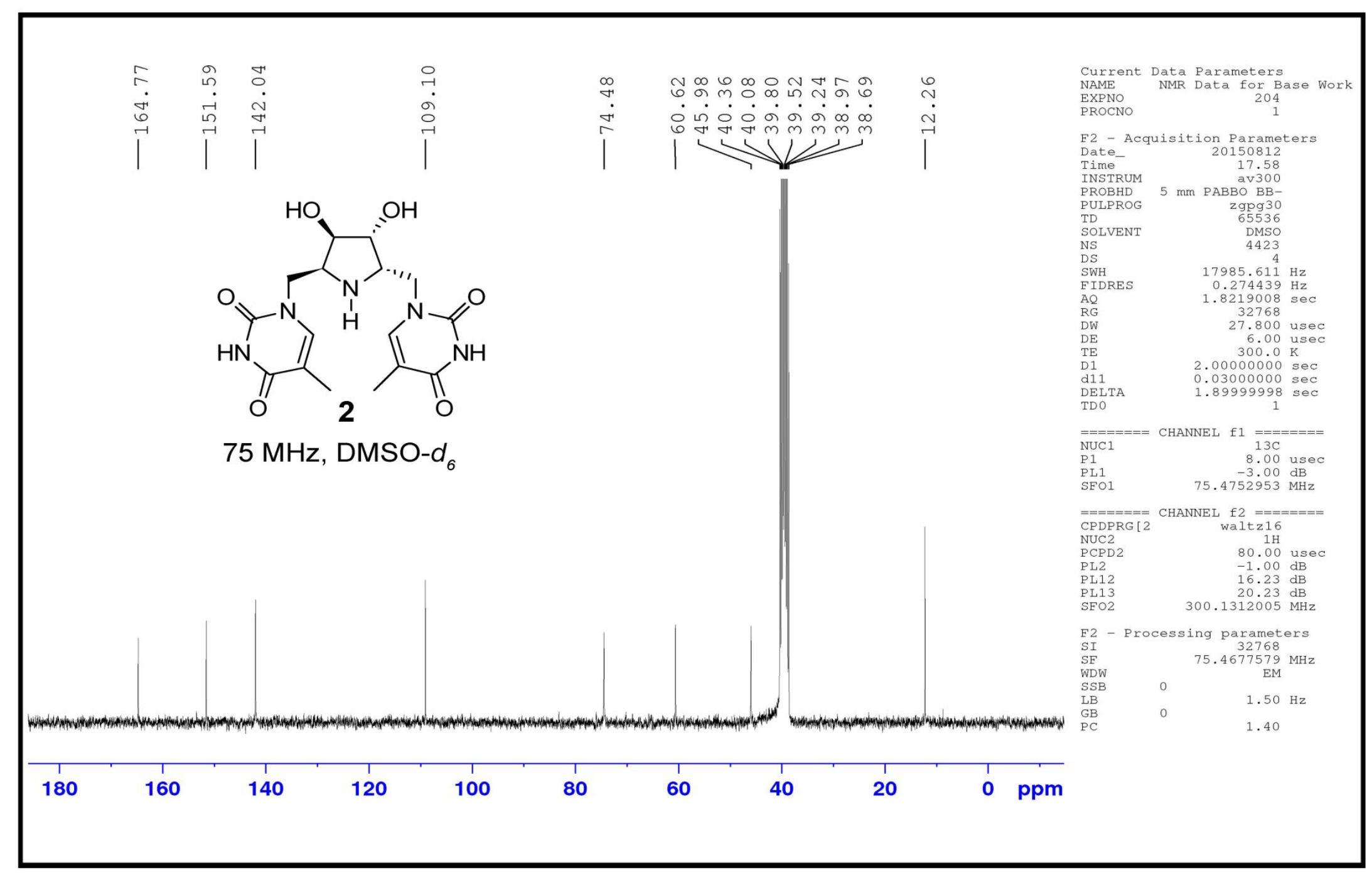

Figure S20: ${ }^{13} \mathrm{C}$-NMR spectrum of compound 2. 


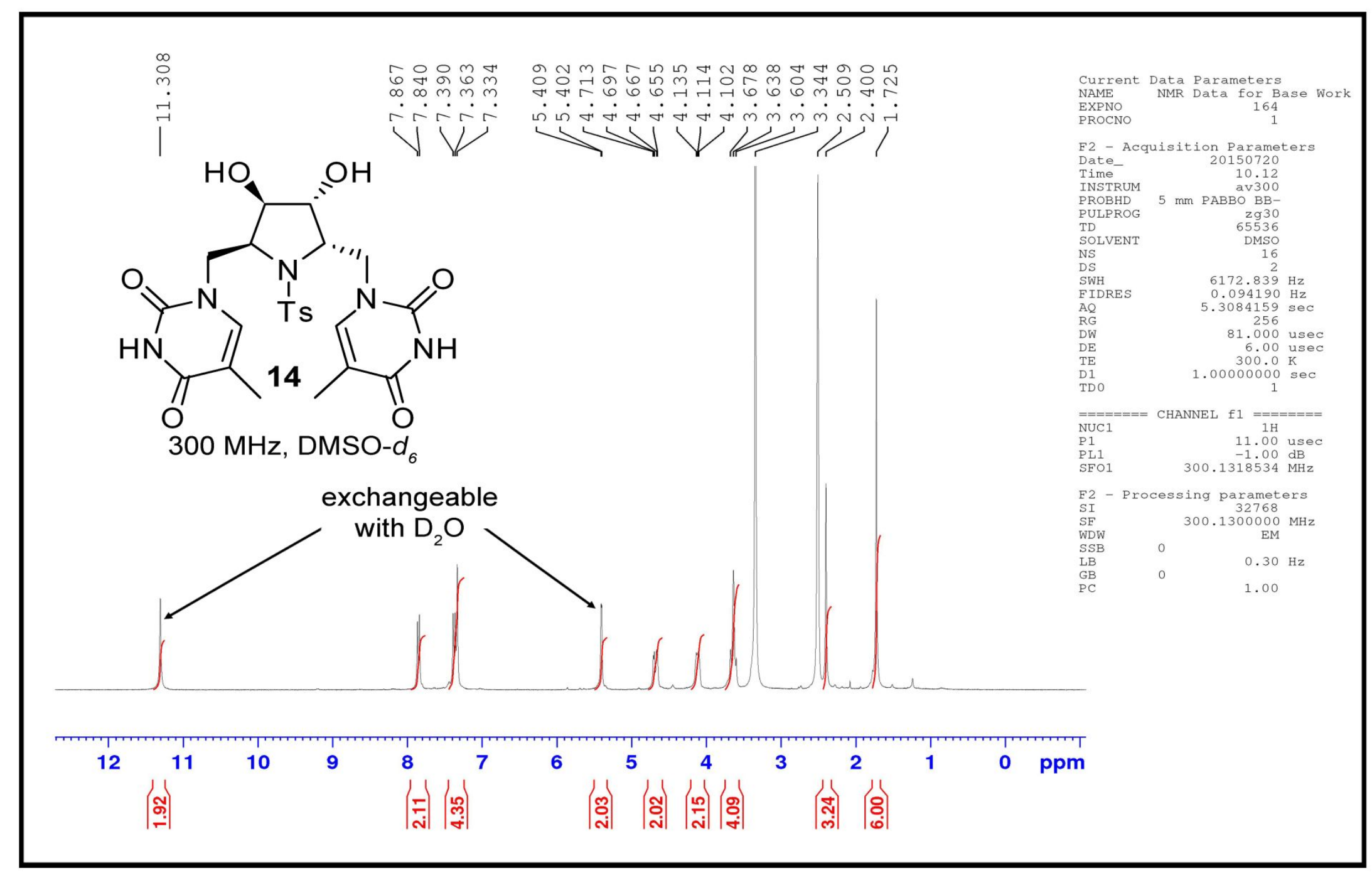

Figure S21: ${ }^{1} \mathrm{H}-\mathrm{NMR}$ spectrum of compound $\mathbf{1 4}$. 


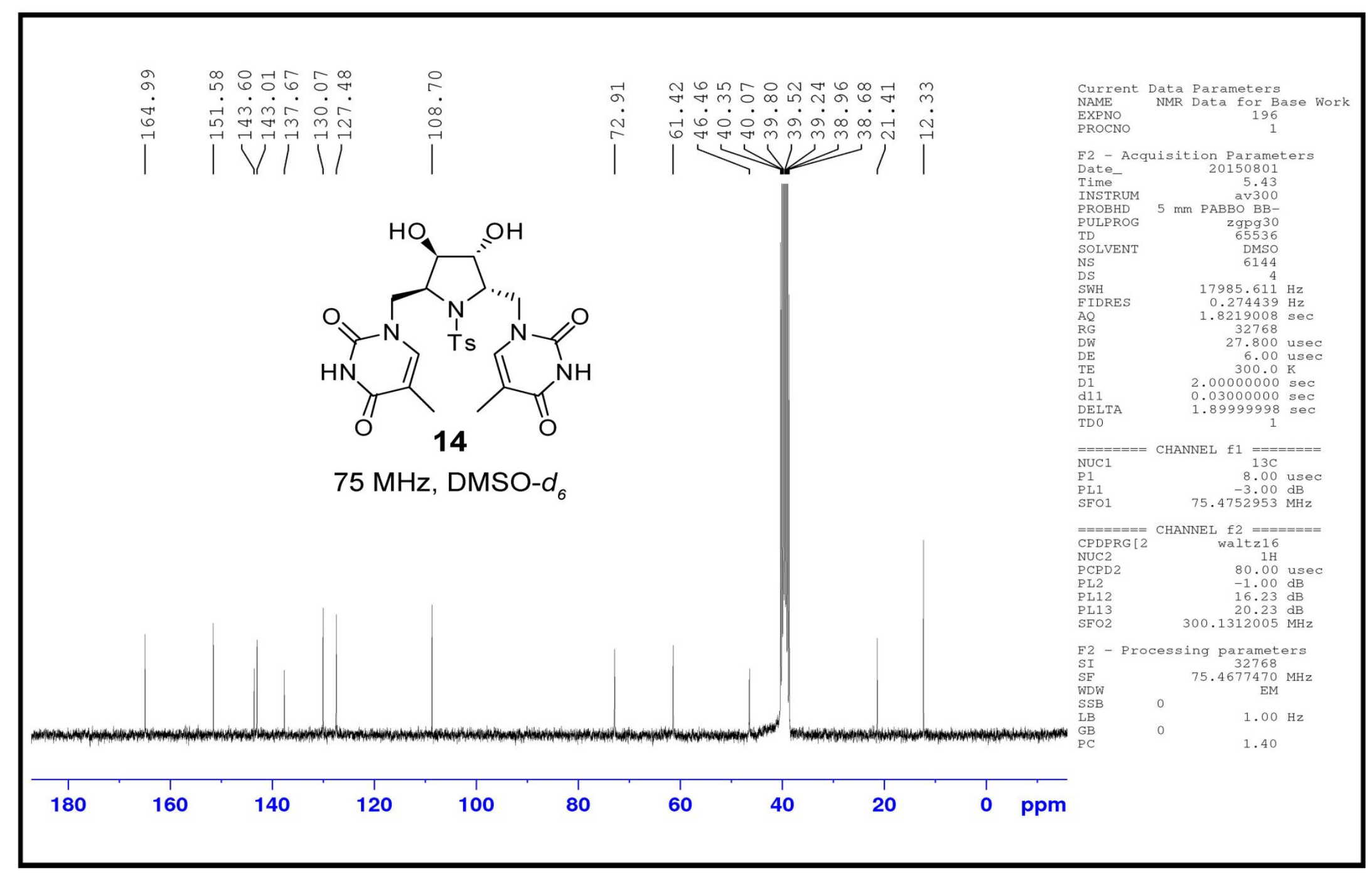

Figure S22: ${ }^{13} \mathrm{C}-\mathrm{NMR}$ spectrum of compound $\mathbf{1 4}$. 


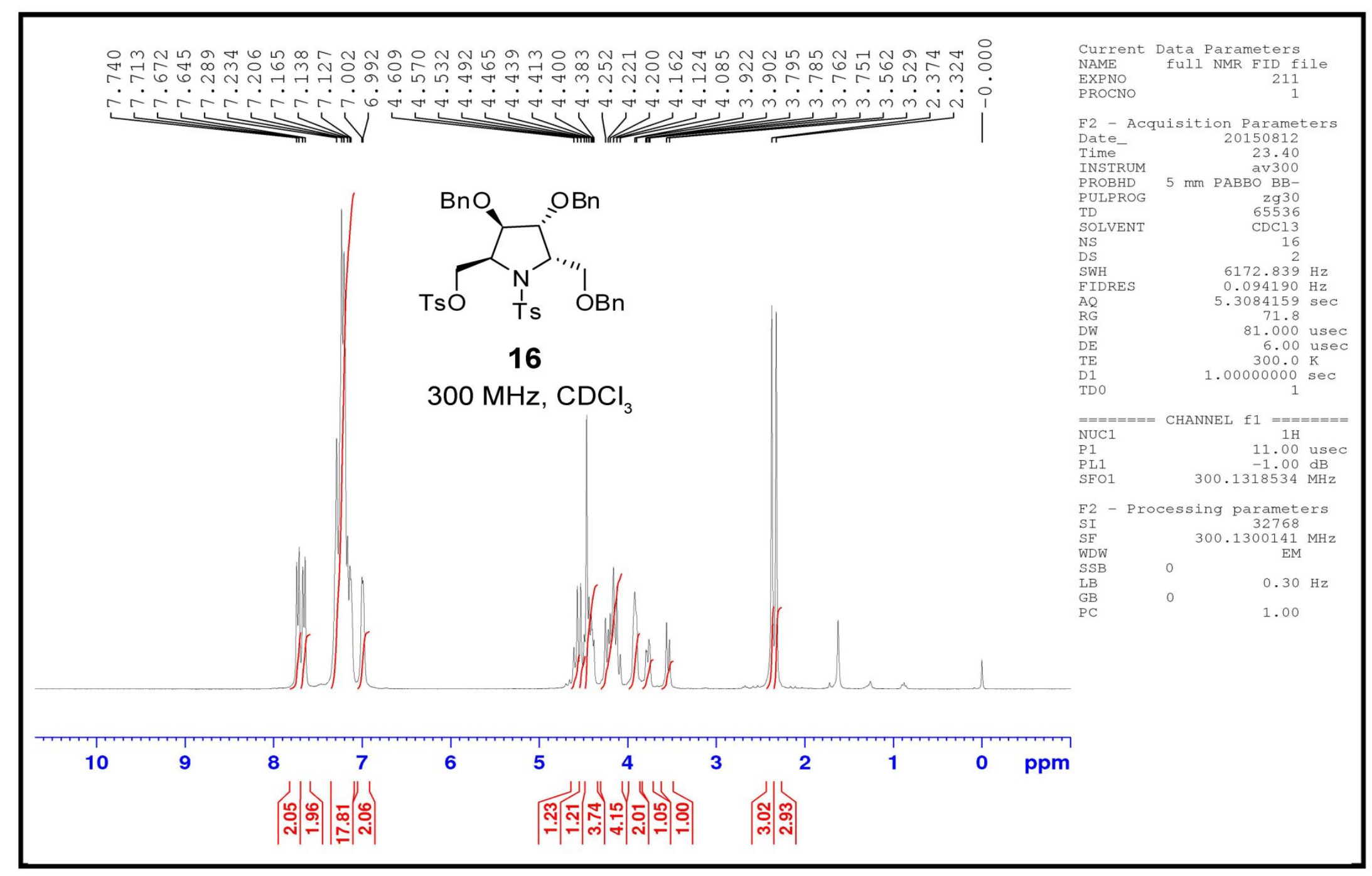

Figure S23: ${ }^{1} \mathrm{H}-\mathrm{NMR}$ spectrum of compound $\mathbf{1 6}$. 


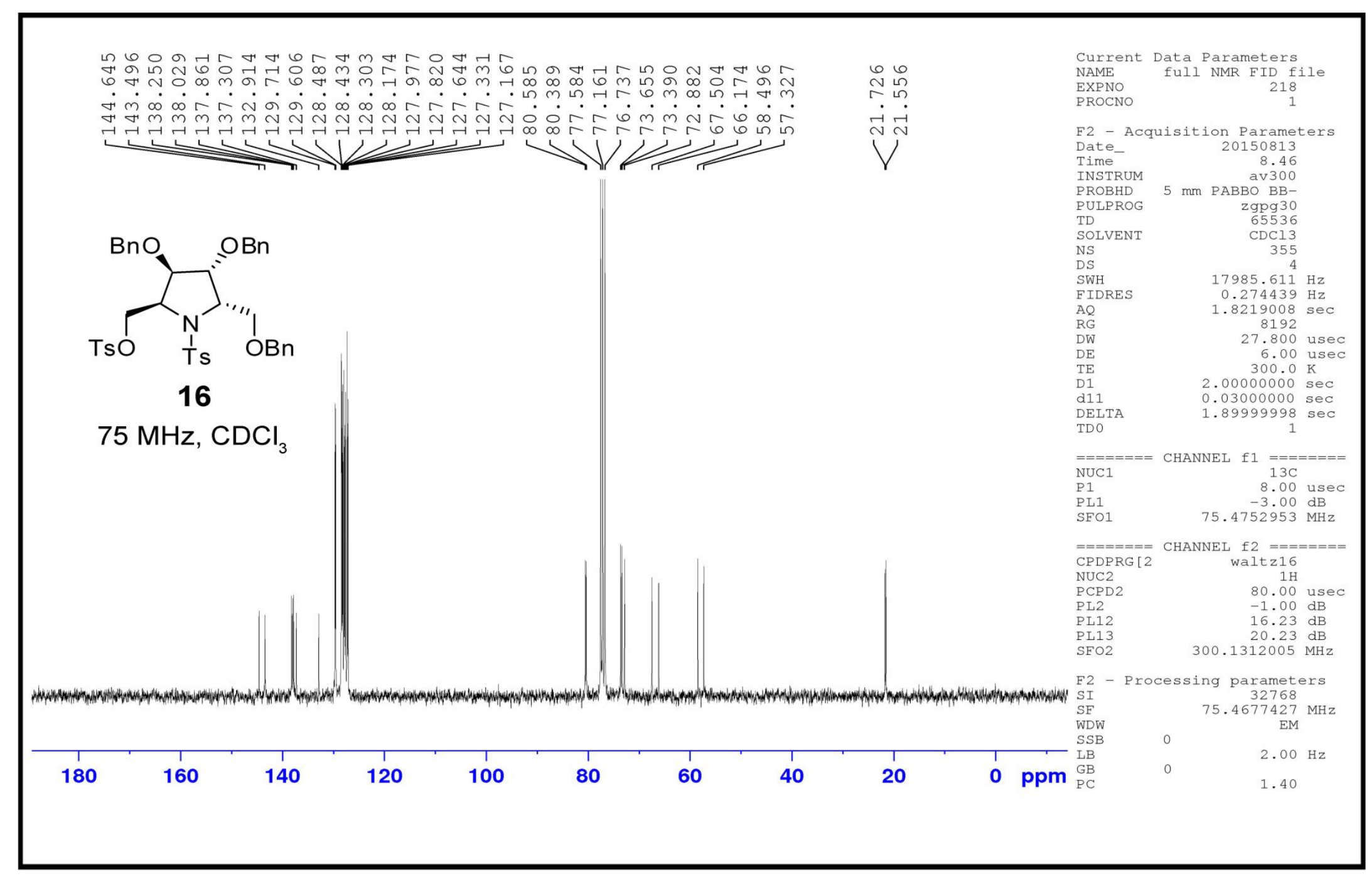

Figure S24: ${ }^{13} \mathrm{C}-\mathrm{NMR}$ spectrum of compound $\mathbf{1 6}$. 


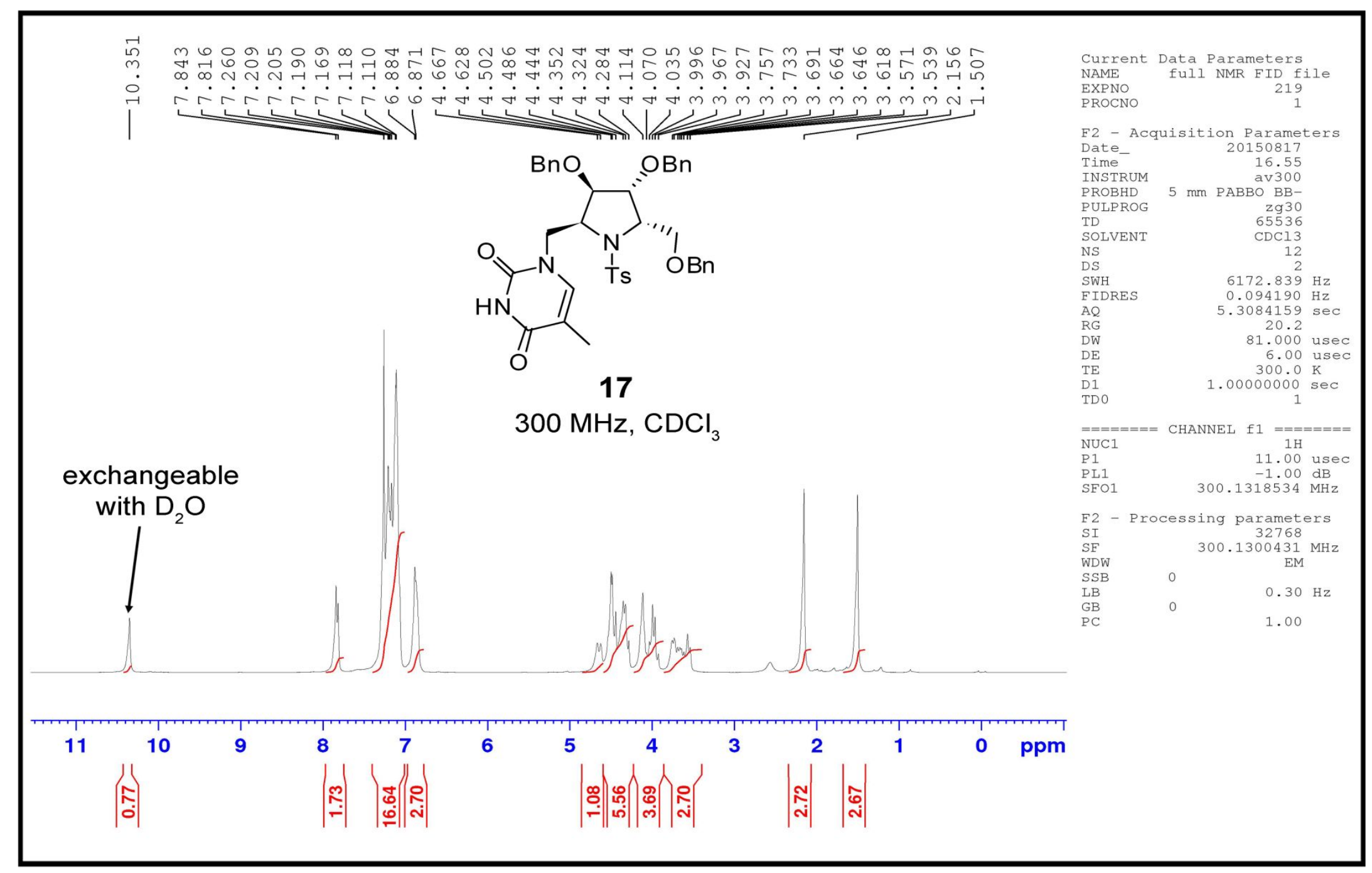

Figure S25: ${ }^{1} \mathrm{H}-\mathrm{NMR}$ spectrum of compound 17. 


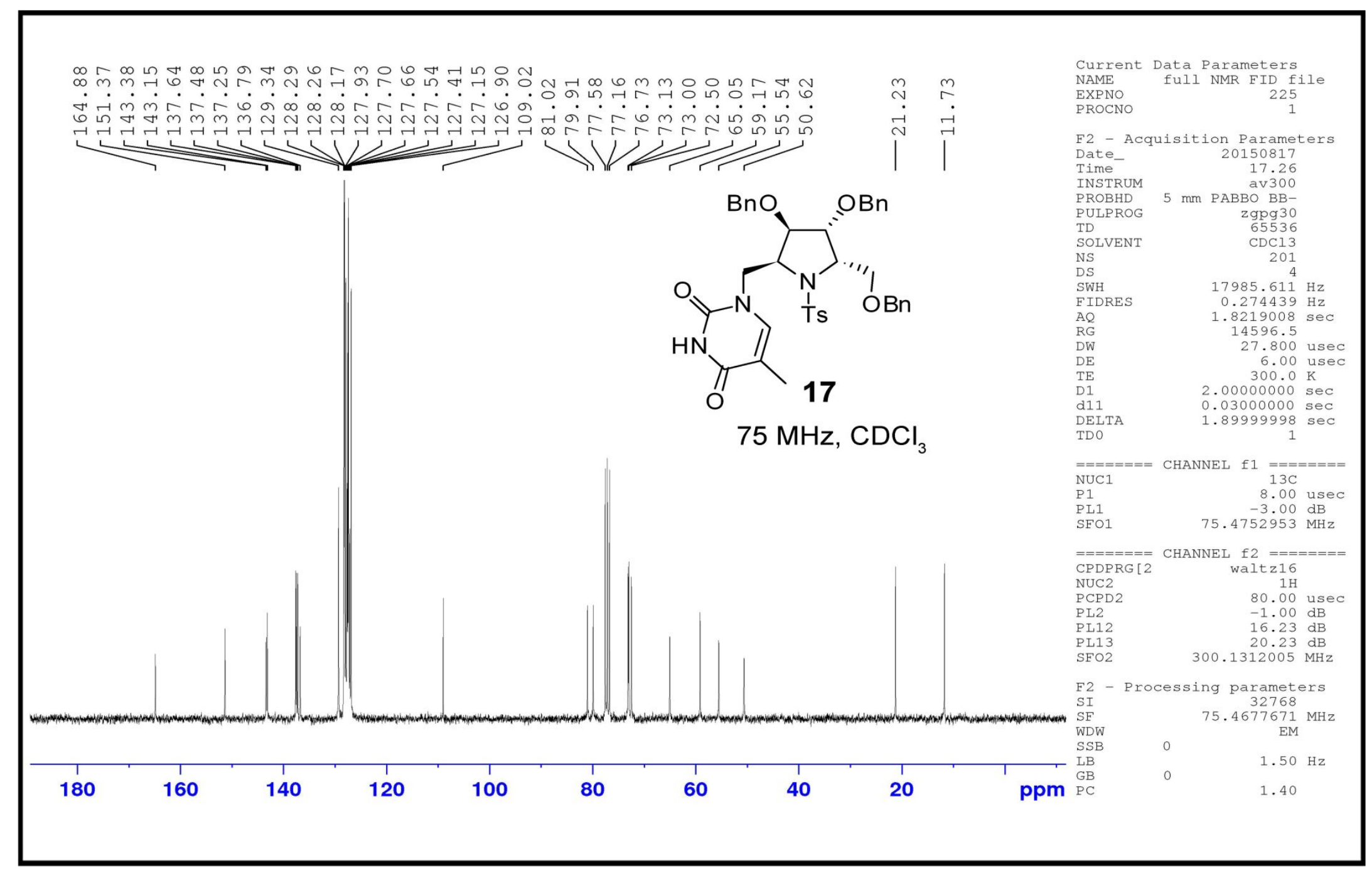

Figure S26: ${ }^{13} \mathrm{C}-\mathrm{NMR}$ spectrum of compound 17. 


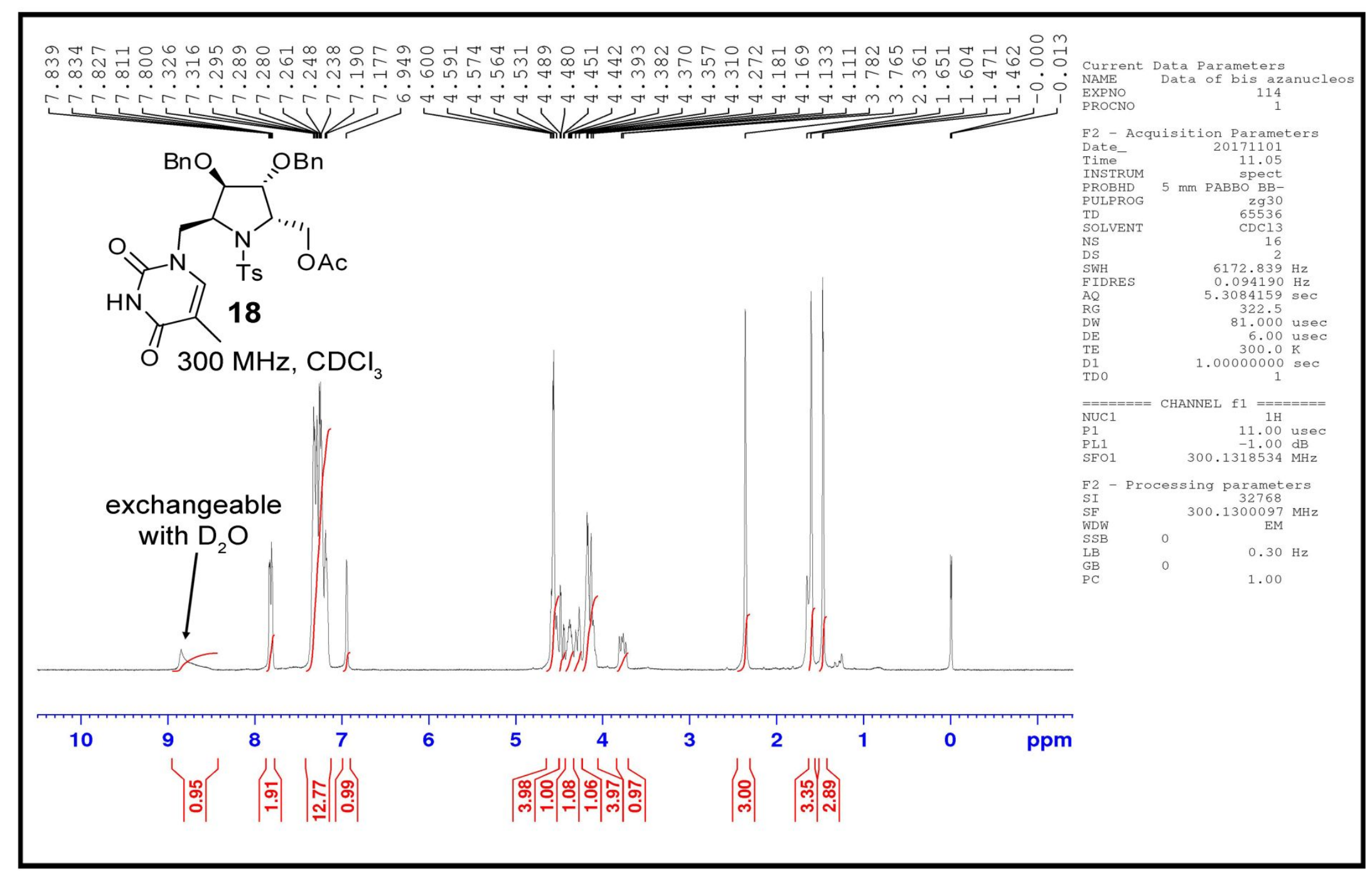

Figure S27: ${ }^{1} \mathrm{H}-\mathrm{NMR}$ spectrum of compound $\mathbf{1 8}$. 


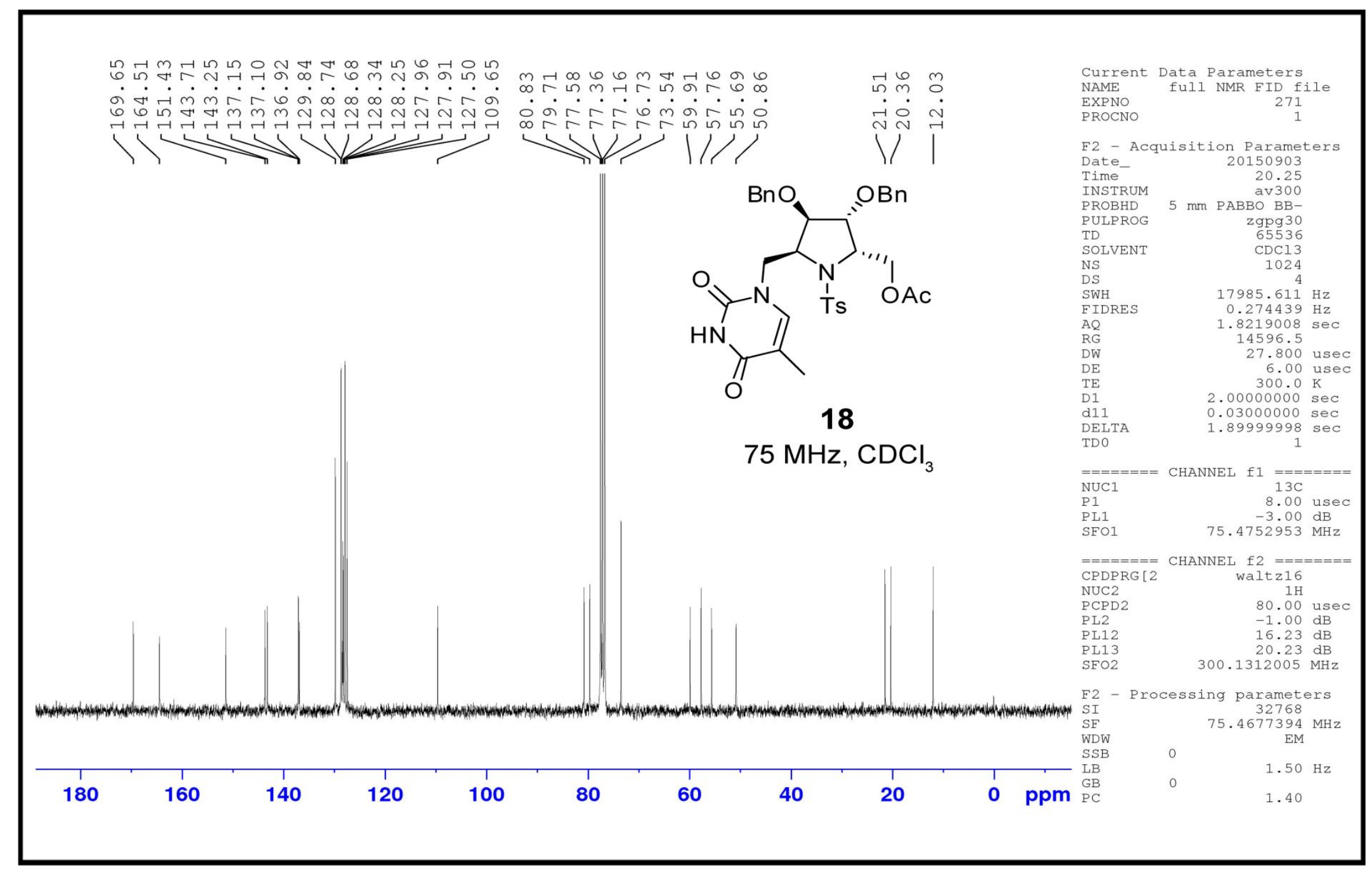

Figure S28: ${ }^{13} \mathrm{C}-\mathrm{NMR}$ spectrum of compound $\mathbf{1 8}$. 


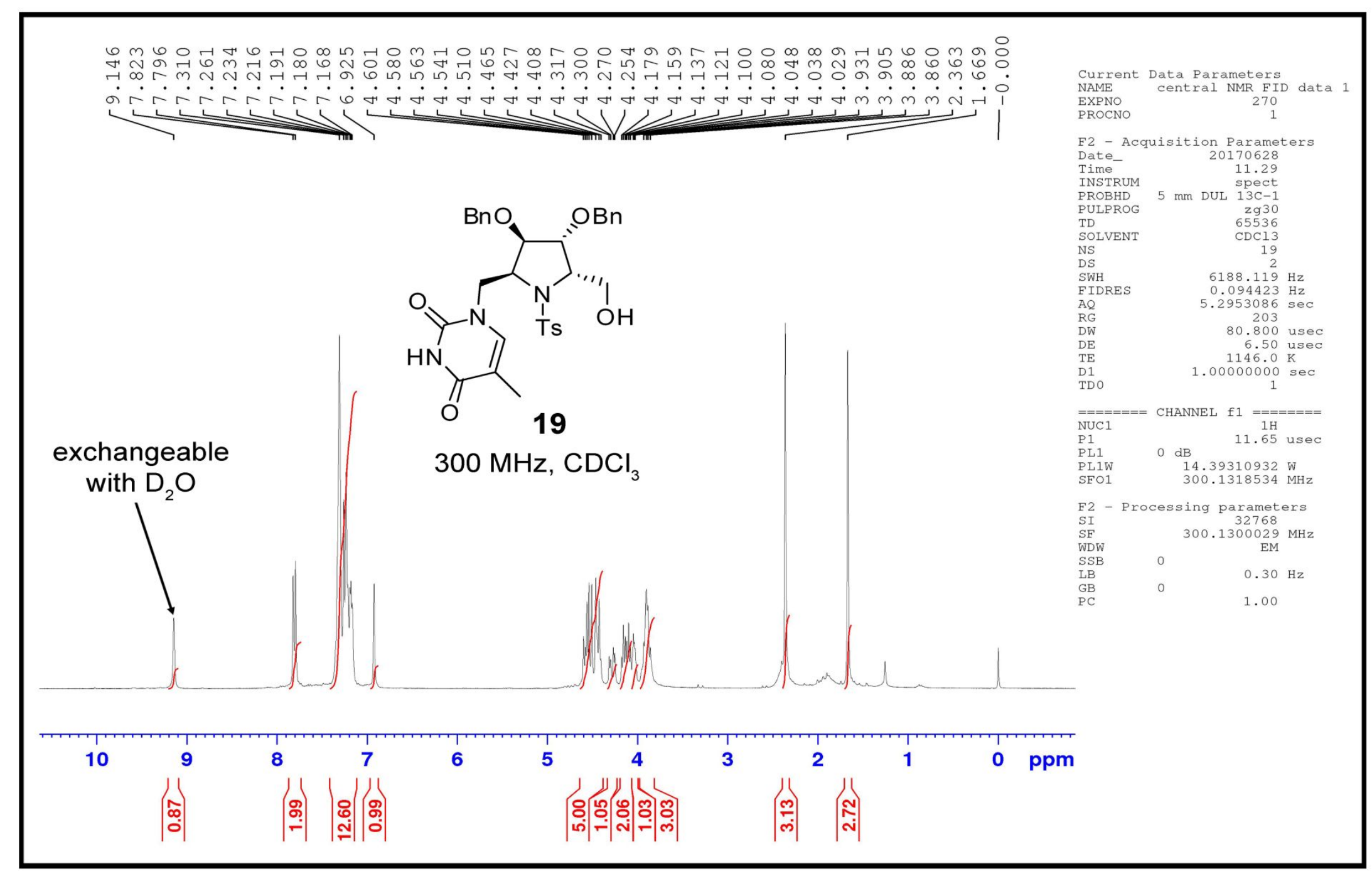

Figure S29: ${ }^{1} \mathrm{H}-\mathrm{NMR}$ spectrum of compound 19. 


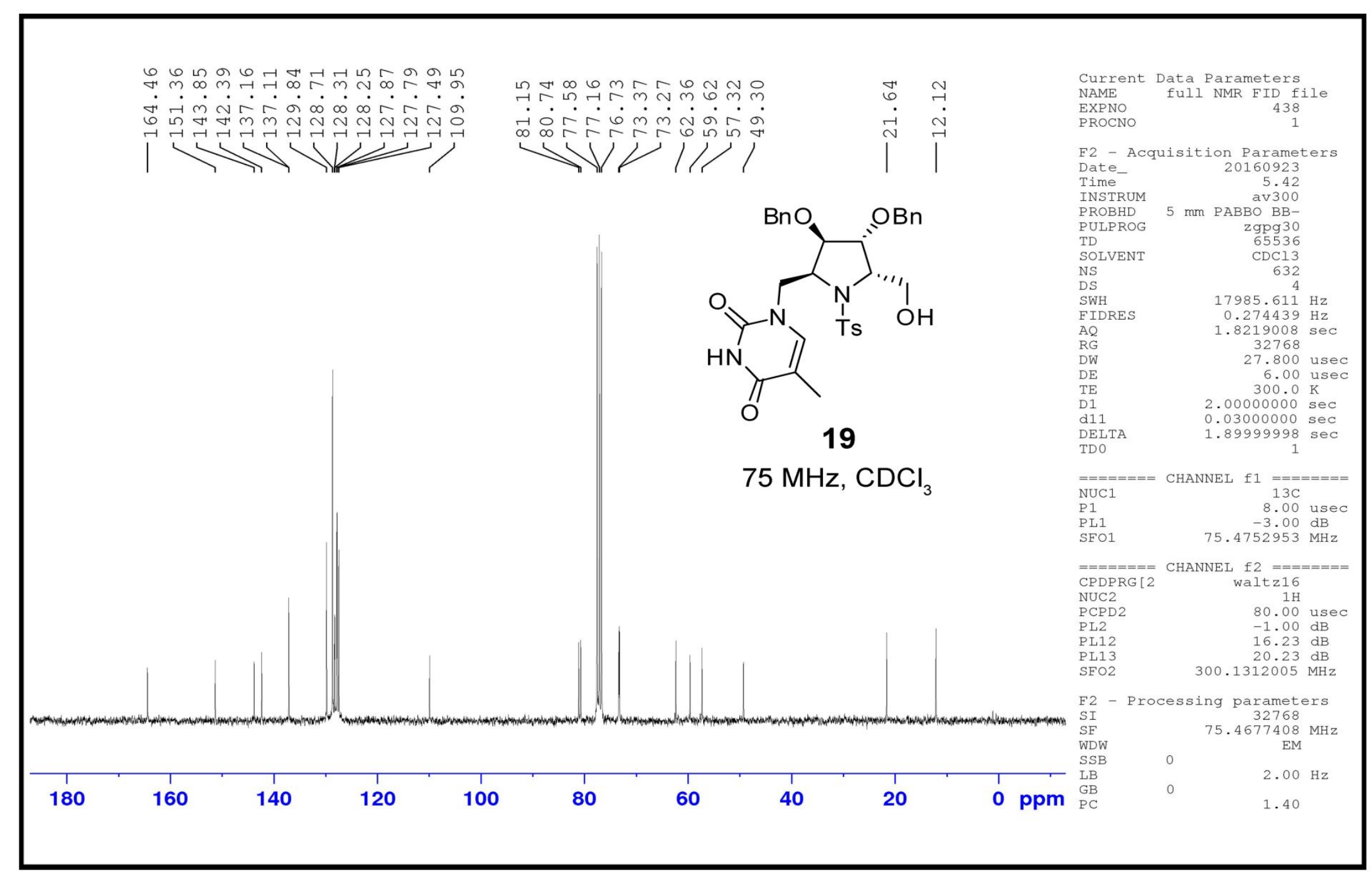

Figure S30: ${ }^{13} \mathrm{C}-\mathrm{NMR}$ spectrum of compound 19 


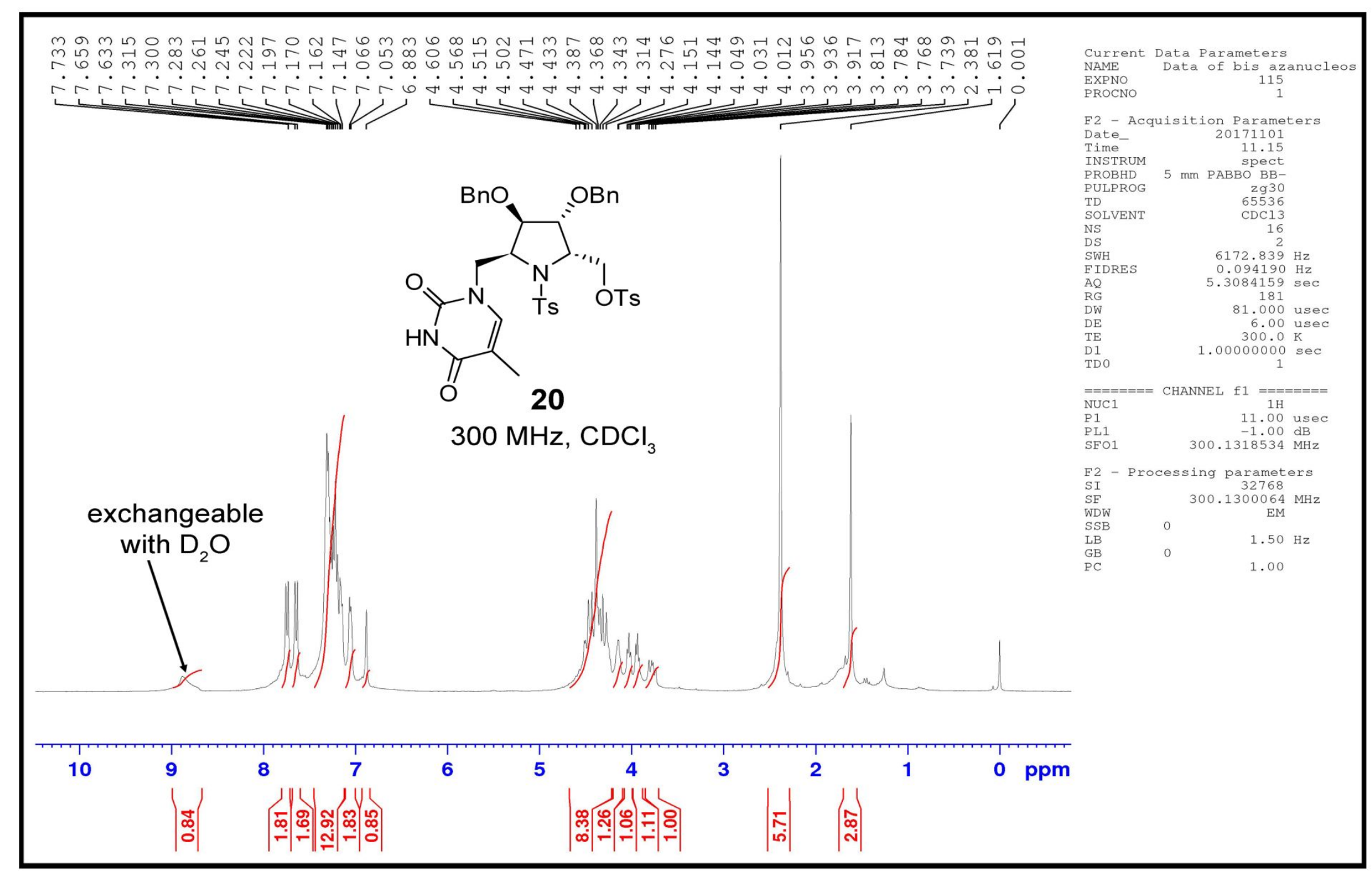

Figure S31: ${ }^{1} \mathrm{H}-\mathrm{NMR}$ spectrum of compound 20. 


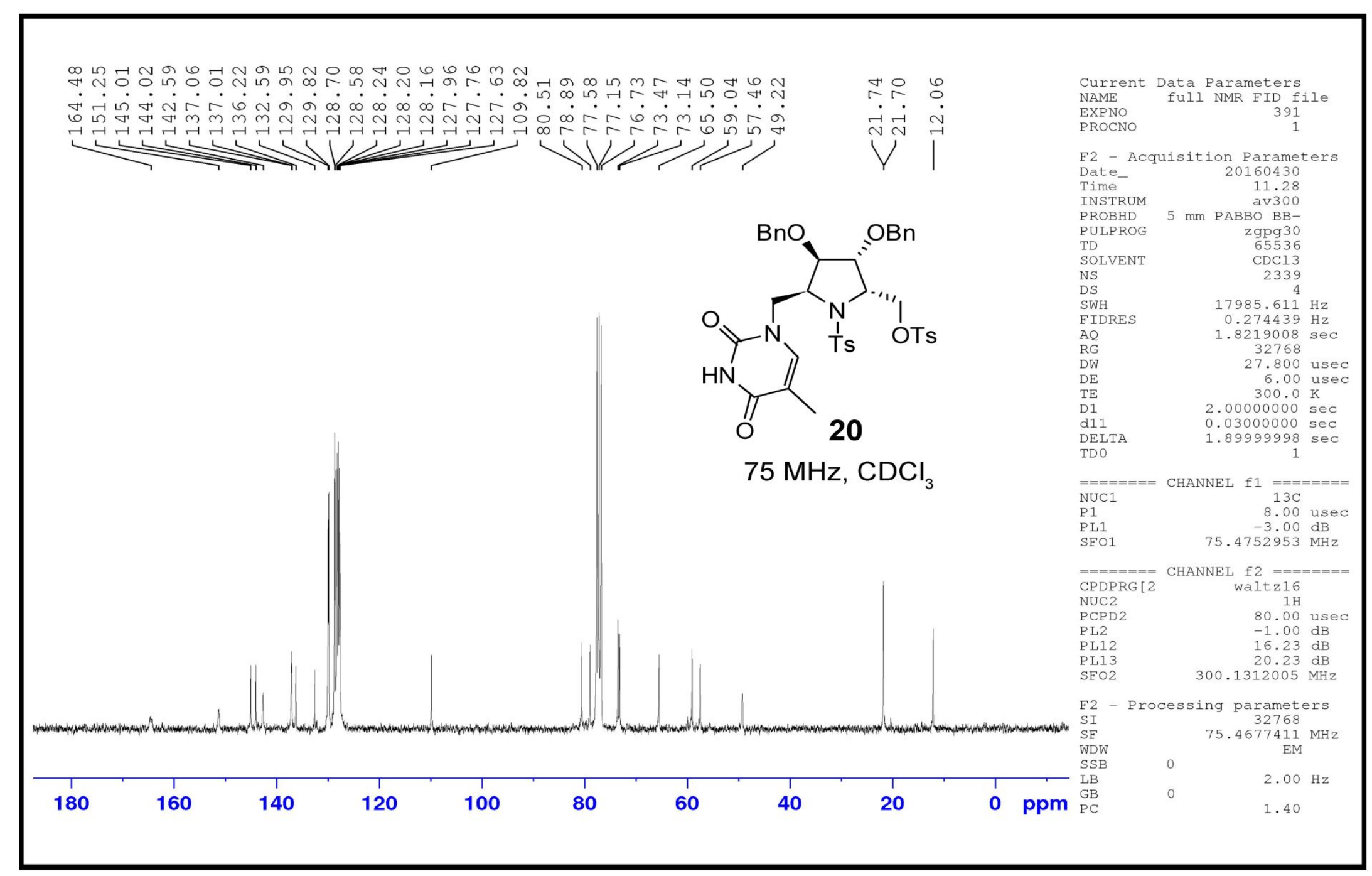

Figure S32: ${ }^{13} \mathrm{C}-\mathrm{NMR}$ spectrum of compound 20. 


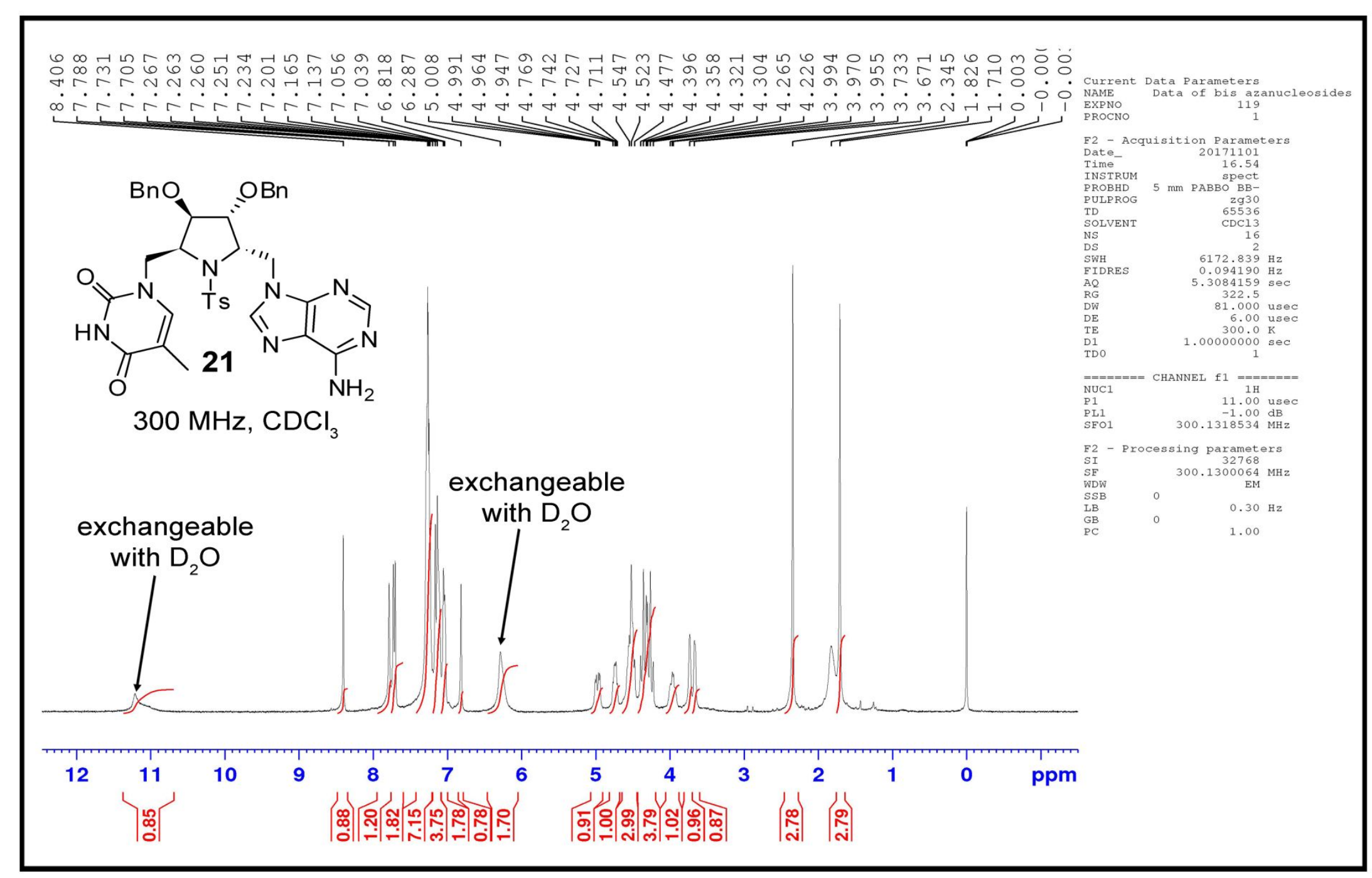

Figure S33: ${ }^{1} \mathrm{H}-\mathrm{NMR}$ spectrum of compound 21. 


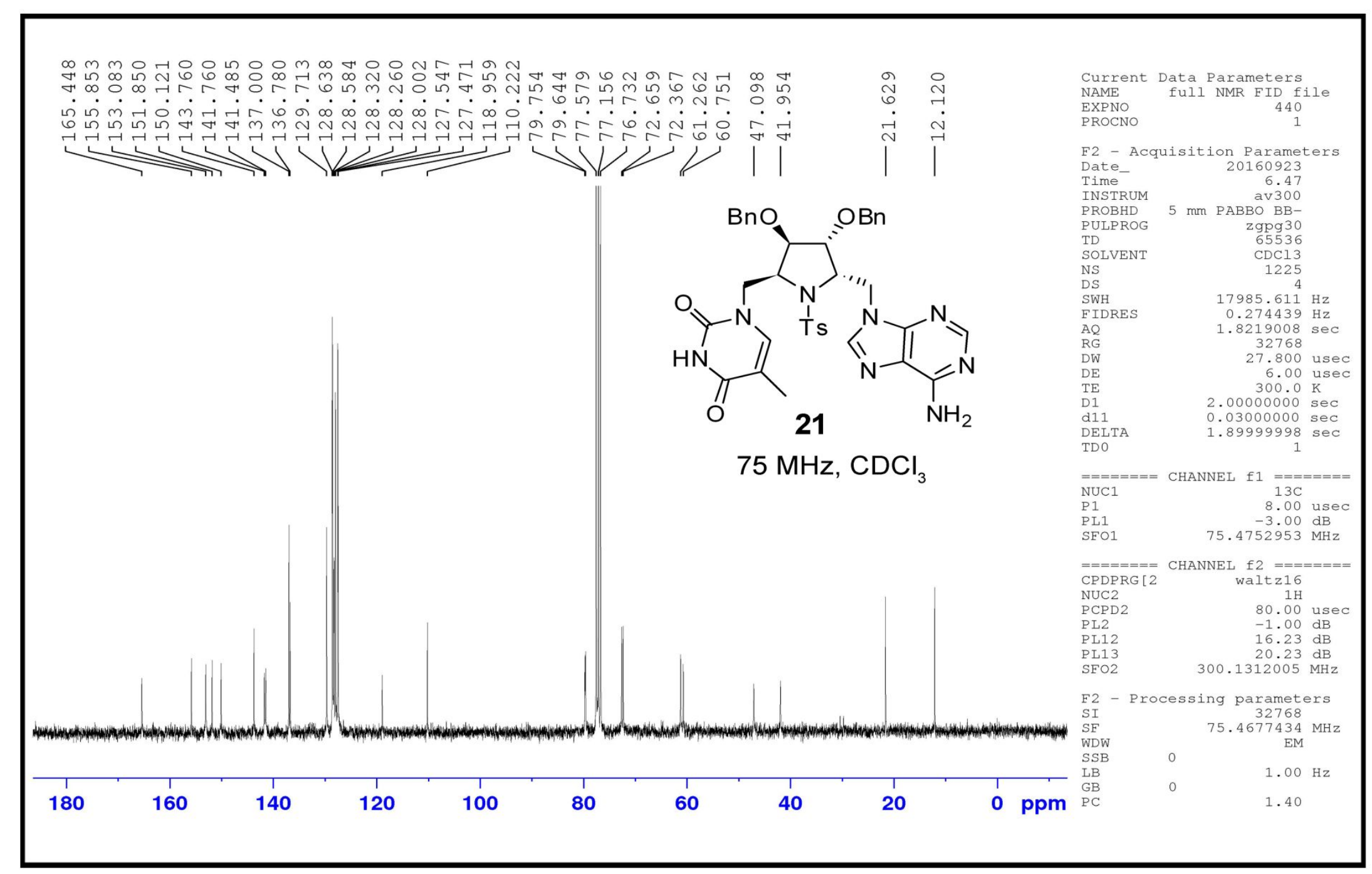

Figure S34: ${ }^{13} \mathrm{C}-\mathrm{NMR}$ spectrum of compound 21. 


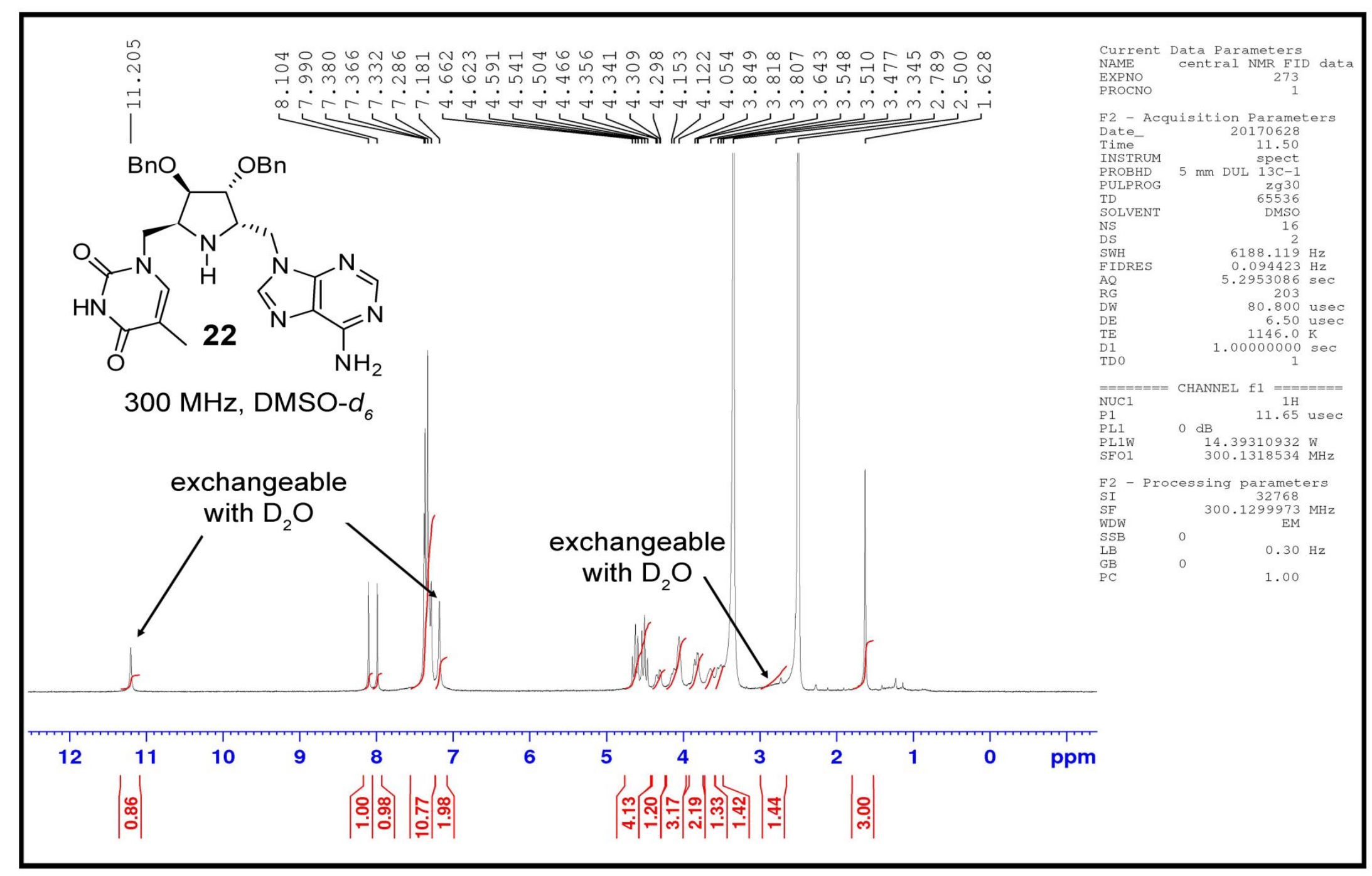

Figure S35: ${ }^{1} \mathrm{H}-\mathrm{NMR}$ spectrum of compound 22. 


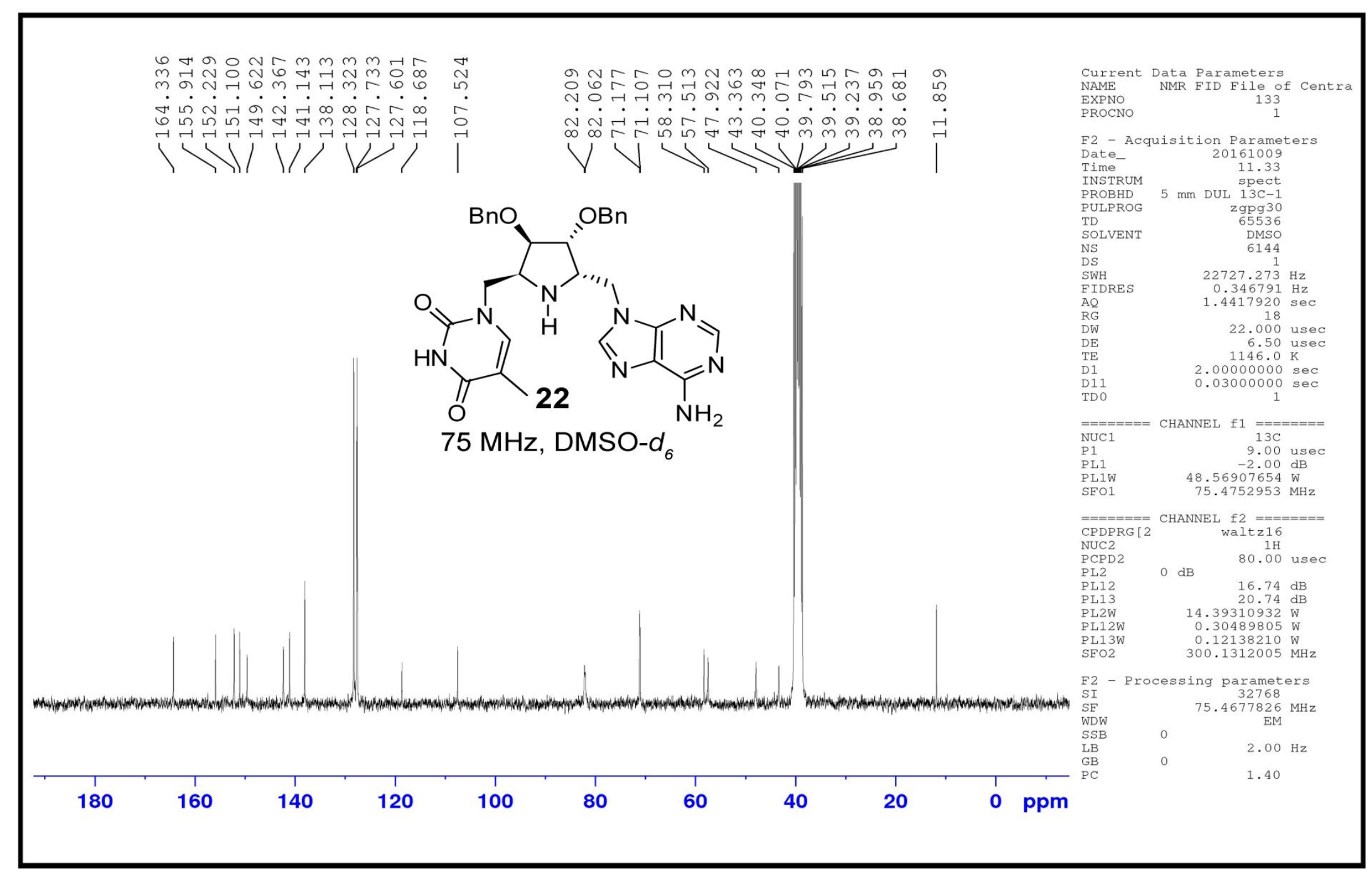

Figure S36: ${ }^{13} \mathrm{C}-\mathrm{NMR}$ spectrum of compound 22. 


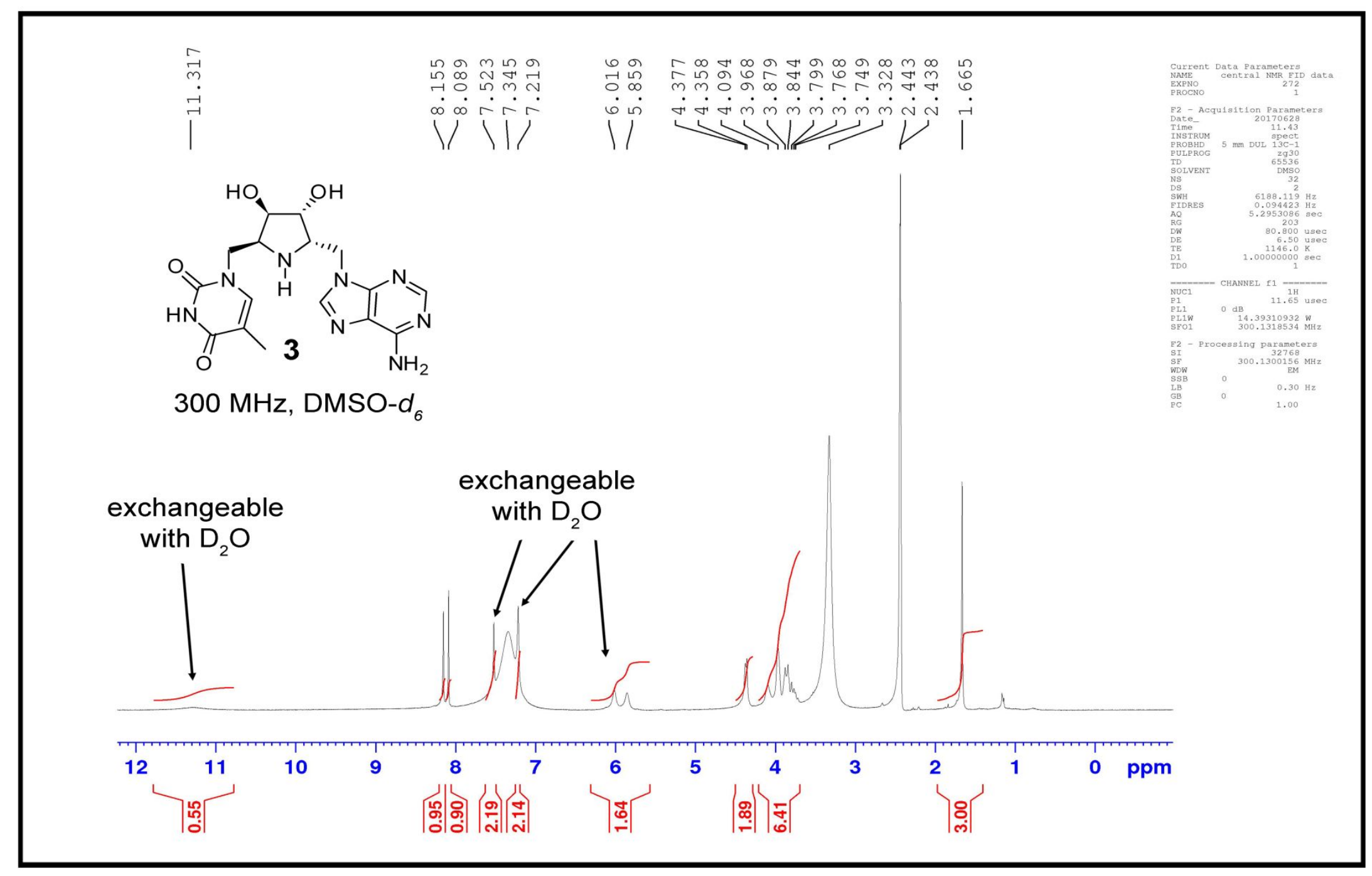

Figure S37: ${ }^{1} \mathrm{H}-\mathrm{NMR}$ spectrum of compound $\mathbf{3}$. 


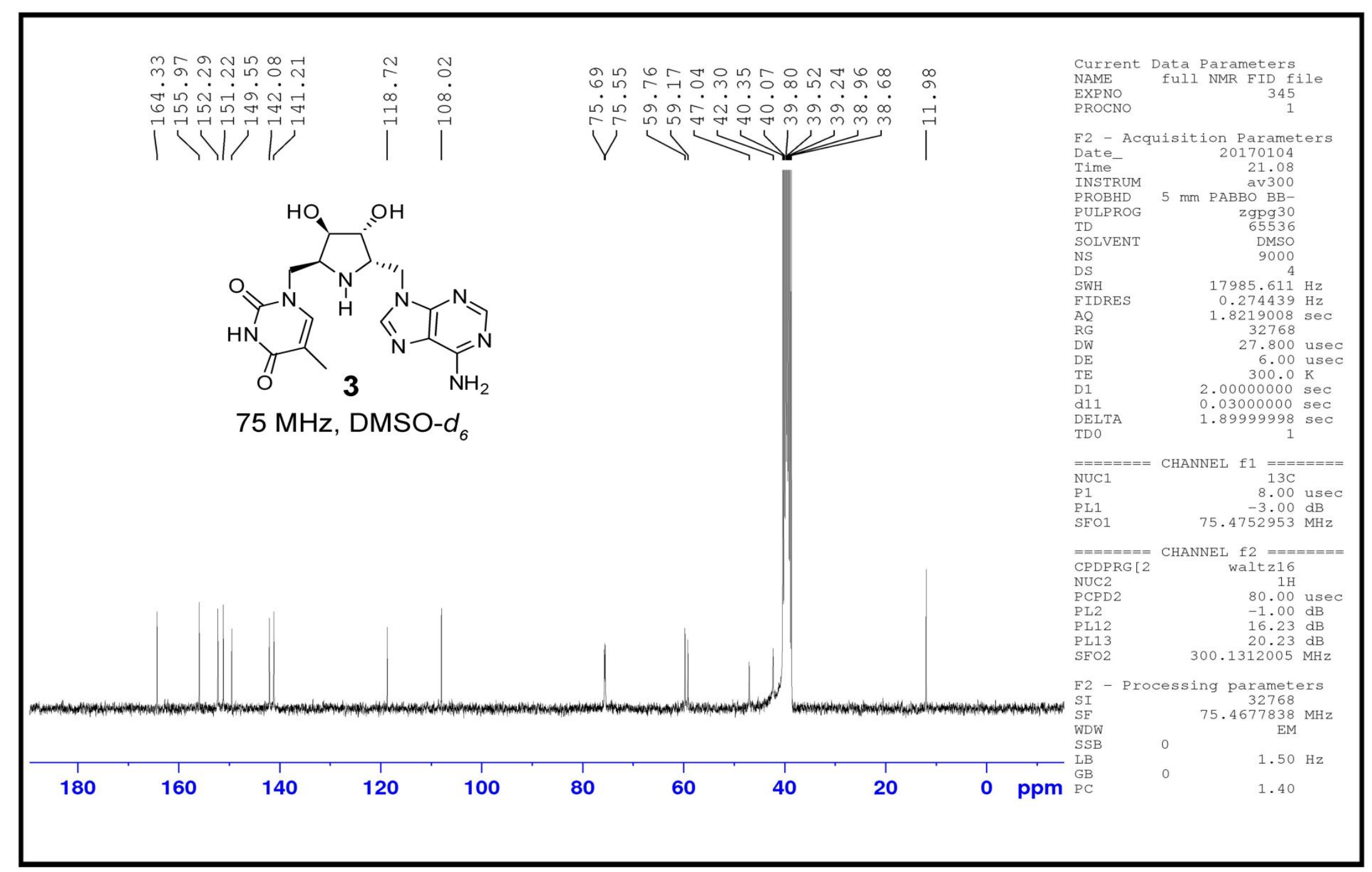

Figure S38: ${ }^{13} \mathrm{C}$-NMR spectrum of compound 3 . 
X-ray Crystallography: Crystals of compounds 2, 10 and 21 were grown by slow evaporation of their solution in 1 M HCl, DMSO-methanol and chloroform-methanol respectively at room temperature. The reported data set was collected by mounting the crystal with paratone oil in a loop. X-ray reflections were collected on Bruker D8 Quest diffractometer with CMOS detector using Mo-K $\alpha$ radiation, generated from the micro-focus sealed tube. Data collection was performed using $\varphi$ and $\omega$-scans of $0.5^{\circ}$ steps at $289 \mathrm{~K}$. Cell determination, data collection and data reduction were performed with the help of Bruker APEX2 (version: 2014.3-0) software. The structures were solved by intrinsic phasing method (SHELXS-97) and refined by full-matrix least squares refinement method based on $\mathrm{F}^{2}$, using, SHELXL-2014. All non-hydrogen atoms were refined anisotropically. All hydrogen atoms were fixed geometrically with their $U_{\text {iso }}$ values 1.2 times of the phenylene and methylene carbons and 1.5 times of the methyl carbon using a riding model. The crystal structure data are deposited to Cambridge Structural Database with CCDC number 2023656, 2023657 and 2023658 for compounds 2,21 and 10 respectively. 
Table S1: Crystal data and structure refinement parameters for 10, 2 and 21.

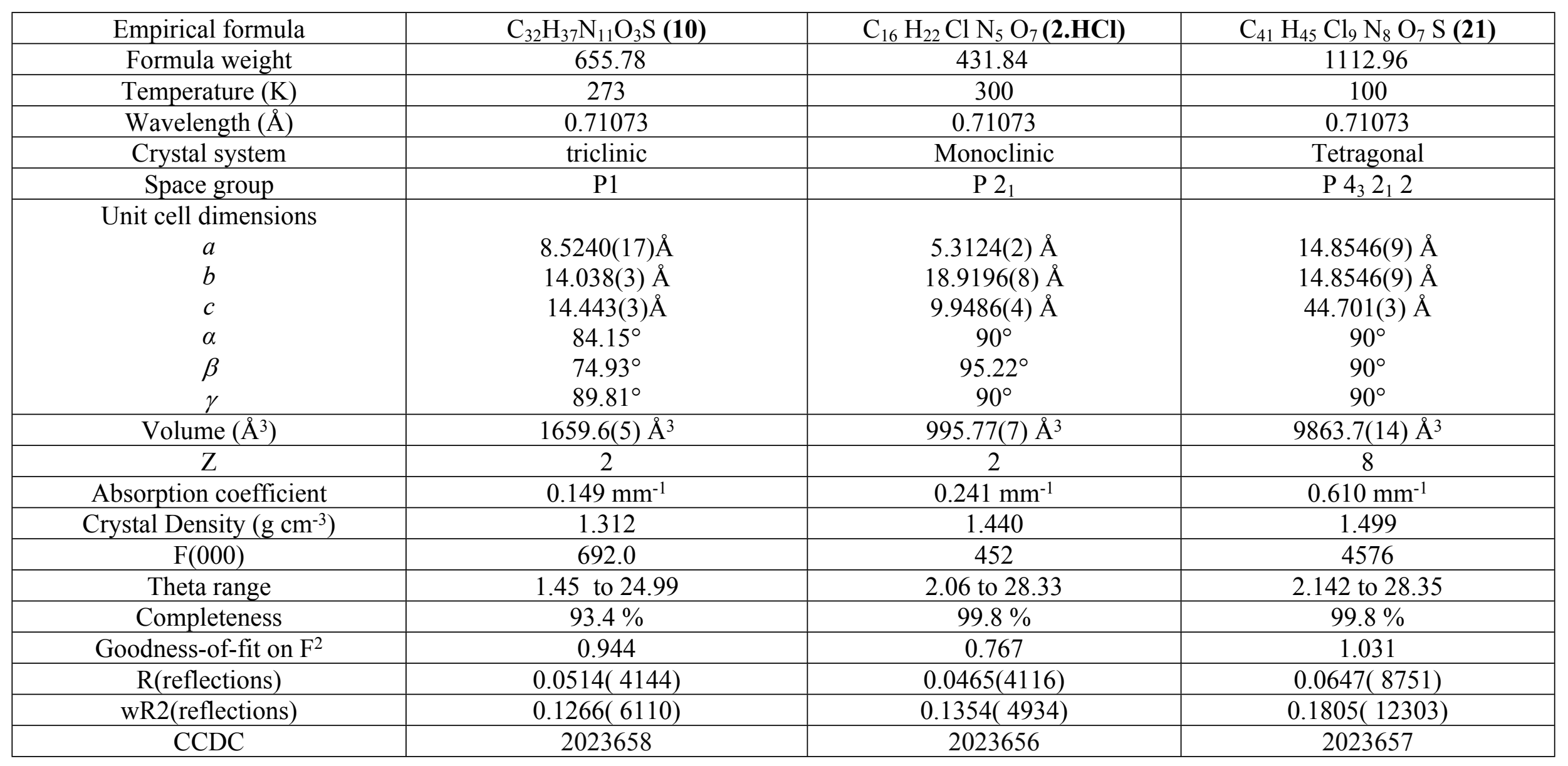


Figure S39: ORTEP plot of the crystal structure of $\mathbf{1 0}$ (at $50 \%$ probability level).

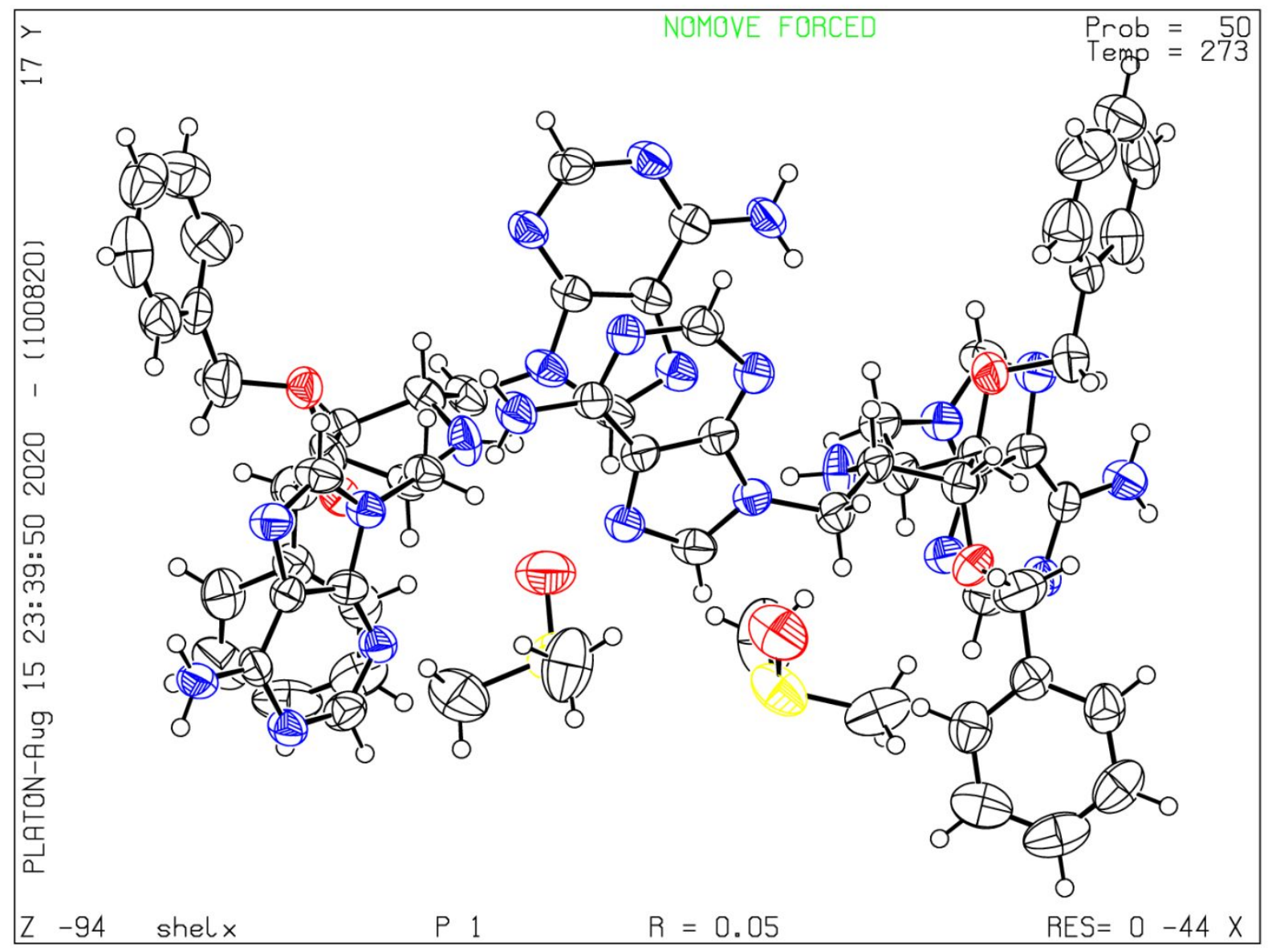


Figure S40: ORTEP plot of the crystal structure of 2.HCl (at 50\% probability level).

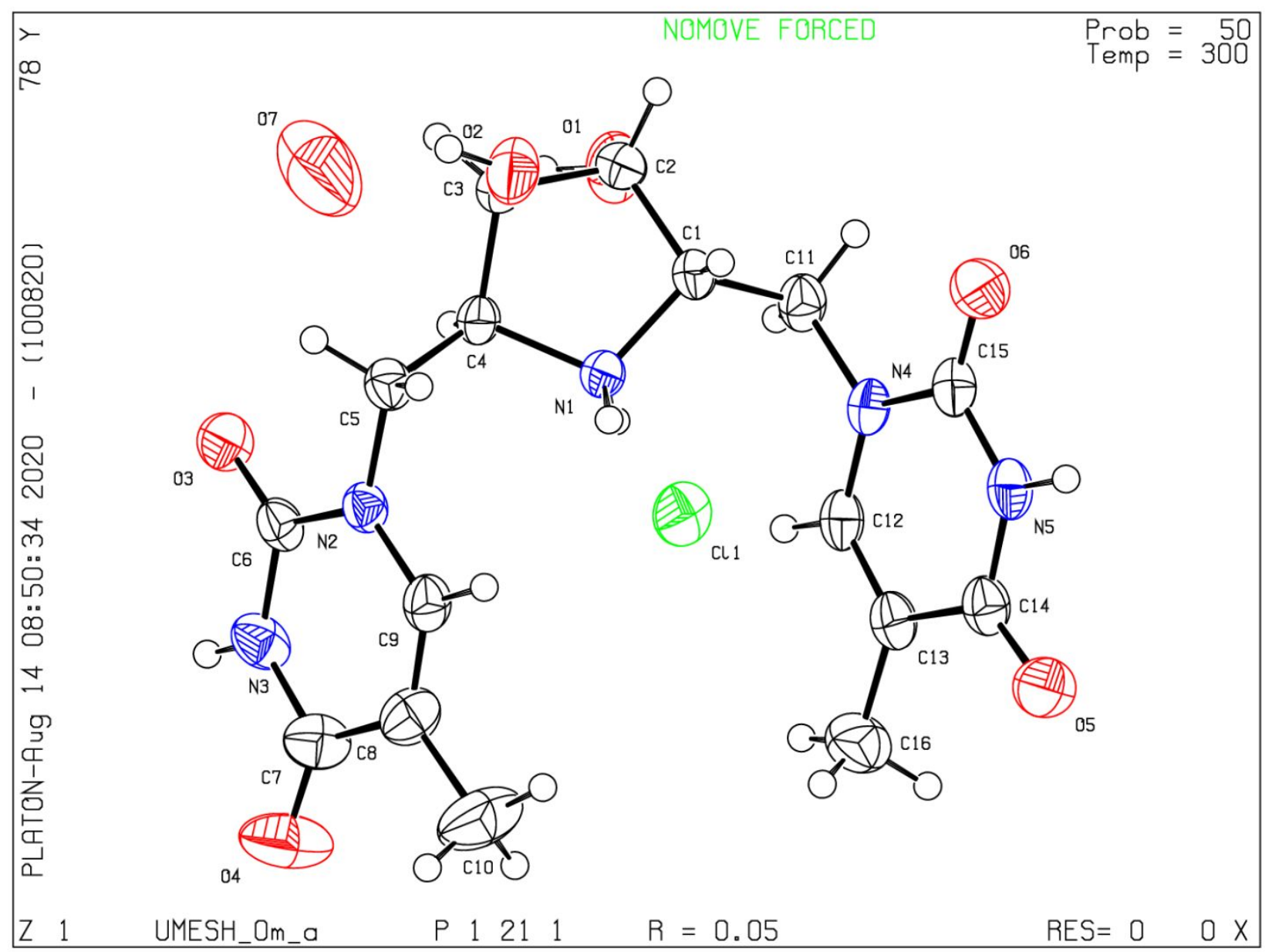


Figure S41: ORTEP plot of the crystal structure of $\mathbf{2 1}$ (at 50\% probability level).

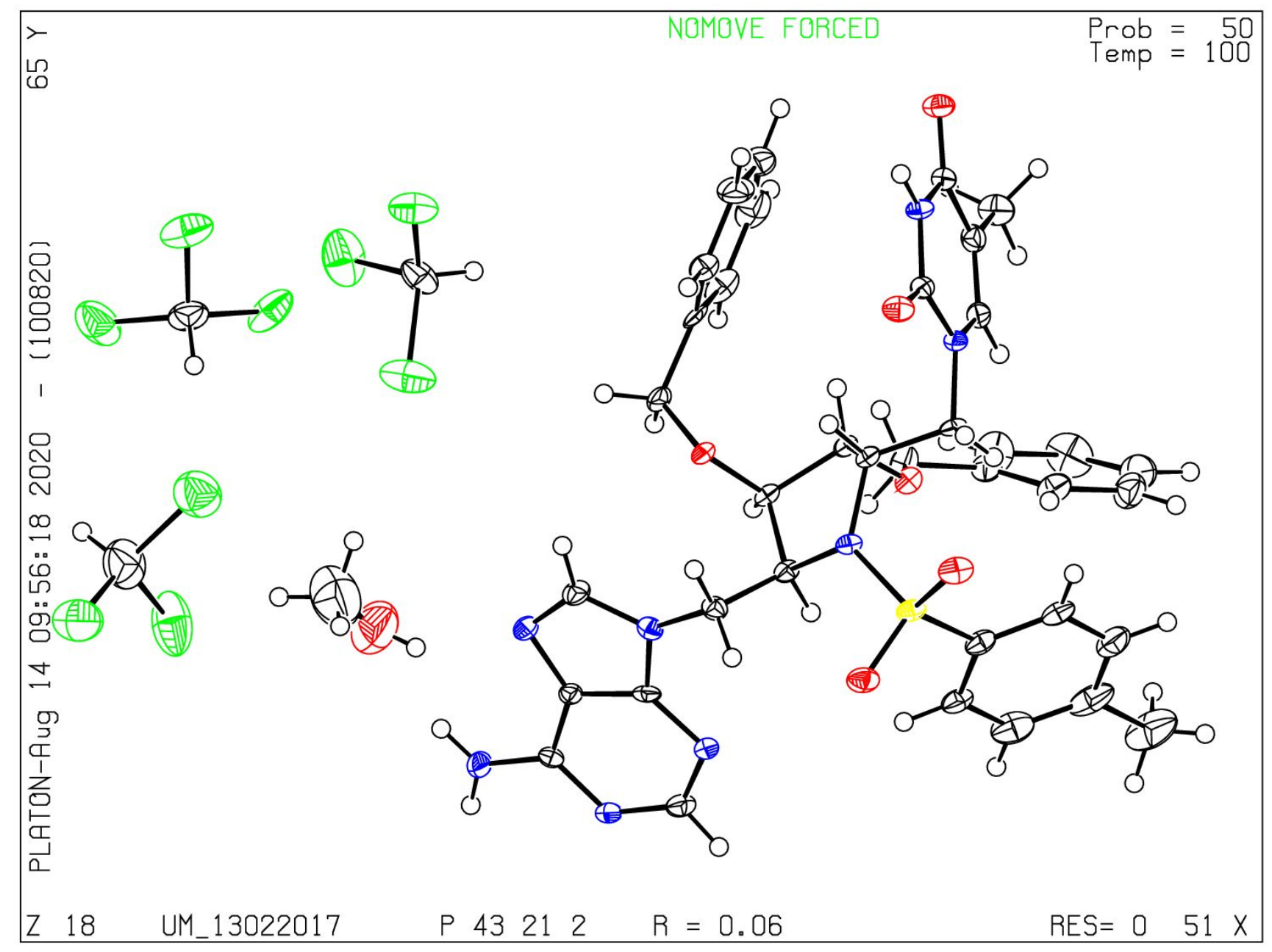

